CITATION: Cole, G. and Stewart, R.A. (2012) Smart meter enabled disaggregation of urban peak water demand: precursor to effective urban water planning. Urban Water Journal, HTTP://DX.DOI.ORG/10.1080/1573062X.2012.716446

\title{
Smart meter enabled disaggregation of urban peak water demand: precursor to effective urban water planning
}

\author{
Graham Cole ${ }^{1,2}$ and Rodney A. Stewart ${ }^{1}$ \\ ${ }^{1}$ Griffith School of Engineering, Griffith University, Gold Coast Campus, Australia \\ ${ }^{2}$ Wide Bay Water Corporation, PO Box 5499, Hervey Bay, Australia
}

\begin{abstract}
The implementation of a smart water metering system in Hervey Bay in 2006-2007 allowed the local water utility to record the hourly water consumption of all its customers. This data availability has enabled a large scale research project to proceed with the aim to disaggregate peak hour, peak day and peak month demand in the water distribution network into primary indoor usage (e.g. shower, washing machine, etc.) and irrigation components. Such information can guide the development of alternative tariff structures and other demand management initiatives aimed at reducing peak demand. This paper details results of the analyis of average hour, peak hour, peak day and peak month consumption data of 2,884 residential customers selected from four District Metered Areas (DMAs) located in the city of Hervey Bay in Queensland, Australia.
\end{abstract}

Key words: hourly consumption profile, peak demand, consumption disaggregation, water demand management, water tariffs, irrigation 


\section{Background}

\subsection{Smart metering and urban water planning}

The concept of smart metering embraces two distinct elements: meters that use new technology to capture water use information; and, communication systems that can capture and transmit water use information as it happens, or almost as it happens (NYSERDA, 2003). Smart water meters essentially perform three functions; they automatically and electronically capture, collect and communicate up-to-date water usage readings on a real-time (or nearly real time) basis (Idris, 2006). The information is available as an electronic signal, which can be captured, logged and processed like any other signal (Britton et al. 2008). In addition, today's data distribution technologies (e.g. using mobile phone technology at the meter / data logger) make it possible to bring this signal readily to any computer (Hauber-Davis and Idris, 2006) and to a central point for analysis or to a website for customer viewing. When interrogated, the data logger downloads the water consumption data to a server, giving a value of water consumption of the required period (Idris, 2006). In this way smart meters can communicate the captured data to a broad audience, e.g. utility managers, consumers and facility authorities.

It should be noted that the richness of water consumption information derived from a smart metering system is dependent on the water meter's resolution and the data logging frequency. Smart metering is an established technology which is now cost-effective enough to be applied to collect, store and distribute real-time water consumption data (Hauber-Davis and Idris, 2006). Beyond consumption data, smart meters in the electricity sector have been identified as offering additional societal benefits including service reliability enhancement, feedback, demand response and new products and services (Neenan and Hemphill, 2008). However, the 
under-explored question of privacy considerations relating to data ownership and management remains (McIntyre, 2008). This should be an area of focus for further research.

Water and wastewater infrastructure planning and management are primarily focused on long-term strategic planning including: developing strategies for holistic catchment water management; system modelling; development assessment and conditioning; priority infrastructure planning; infrastructure charges, policy and schedules; growth management; process assessment; research and development; and regional planning. There are significant implications of smart metering systems for improving current practices of infrastructure planning and management. Related to this study, smart meter enabled diurnal pattern data of water demands at a household level assisted in understanding the extent of irrigation demand during peak hour and day periods. Such information is essential for better restriction regimes, demand management programs or new paradigms of water tariffs (e.g. Cole, 2012).

\subsection{Residential water diurnal demand patterns}

The development of enhanced urban water demand forecasting and planning requires more detailed information on how, when and where residential water in consumed (e.g. shower, washing machine, irrigation, etc.) (Mayer and DeOreo, 1998; Willis et al. 2009). This detailed knowledge of water consumption can provide a greater understanding on the key determinants of each and every water end use, and in return, will allow for the development of improved long-term forecasting models (Blokker et al., 2010). Although there is a growing body of work that demonstrates the influence of various interventions (e.g. water efficient stock) on reduced household water demand (Athuraliya et al. 2008; Beal et al. 2010; Willis et al. 2010; Fidar et al. 2010), there is limited data characterising the changes to peak daily and hourly flows. Of significant interest is how a reduction of peak demand could alleviate 
pressure on current supply network infrastructure and potentially defer the associated infrastructure upgrade costs. Diurnal usage patterns have been used to identify trends and peaks in water (e.g. Willis et al. 2011a) and energy (e.g. Firth et al. 2008) consumption over time. In terms of diurnal water use, these patterns have aided in the characterisation of daily water consumption trends across different socio-demographic groups and varying climatic regions (Beal et al. 2011; Willis et al. 2011a). Diurnal patterns and associated peak demand periods provide valuable information on demand flow rates (per capita) which are vital empirical input parameters for configuring network distribution models as well as for integrated urban water planning (e.g. Makropoulos et al. 2008). Stewart et al. (2010) also note that this type of peak demand analysis can provide valuable information to water utilities to address issues such as demand management planning, billing, asset management and hydraulic engineering based problems.

\subsection{Peak hour and day residential water demand}

Residential water use reflects the pattern and routines of daily life and for this reason there is a morning and afternoon peak demand period where consumption is highest during each 24 hour period. McDonald (2007) refers to the demand for water as '...the interaction of three cycles plus some semi-random perturbations'. The first cycle is the daily life cycle revolving around work, school etc. The second cycle is the variation attributable to weekend activities and the third cycle is the annual progression of the seasons and their influence on water use. The semi-random perturbations are the influence of weather, consumer education and conservation on water use.

People generally have a series of regular water use habits that occur in the morning and afternoon/evening which are normally repeated (Kappel and Grechenig, 2009). Consumption 
concentrated during these two periods results in daily peak demand periods. Figure 1 shows a typical daily water consumption pattern with well defined morning and evening peaks.

\section{[INSERT FIGURE 1]}

During any series of defined time periods there will be one period with the highest volume of consumption, for example during the day there will be a peak hour and during the year a peak day and a peak month with the highest consumption (Carragher et al. 2012). For the purpose of this study, the definitions listed in the Planning Guidelines for Water Supply and Sewerage produced by DERM (2010, p3.) have been applied, as follows:

- Peak hour demand: Peak hourly demand a system will be called on to deliver.

- Peak day demand: Maximum demand in any one day of the year.

While water infrastructure planning and design parameter definitions vary slightly internationally, they all similarly consider a peak hour and day consumption and/or factor increase on the average day consumption. Information collected from smart meters allows better understanding on hourly, daily, monthly and yearly profiles of water consumption; such understanding is undoubtedly the precursor to a new paradigm of optimised water infrastructure planning and asset management.

\subsection{Methods for identifying residential consumption end uses}

\subsubsection{The end use study approach - various snap shots of demand}

Residential water use in Australian urban areas has historically included a significant outdoor component and various water end-use studies have been undertaken to measure indoor and outdoor use as distinct components of total consumption (Loh and Coglan, 2001; Willis et al. 
2010; Beal et al. 2011; Makki et al. 2011; Willis et al. 2011a; Willis et al. 2011b). These studies are usually based on data collected by recording the consumption of a small number of dwellings (i.e. 100-300 households) at very short data recording intervals (i.e. 5-10 seconds) over a short to medium time period (i.e. 2 week periods in summer and winter periods) and using flow trace software to determine each usage type (i.e. toilet, tap, etc.).

Table 1 details the indoor residential end uses of water consumption reported by Loh and Coghlan (2003) in Perth, Australia. At this time in Perth, outdoor consumption (i.e. 707 $\mathrm{L} / \mathrm{hh} / \mathrm{d}$ ) was actually higher than indoor (i.e. $523 \mathrm{~L} / \mathrm{hh} / \mathrm{d}$ ) with the majority share of this outdoor consumption being used for irrigation purposes. More recently, an end-use study in Queensland, Australia completed by Willis et al. (2009) showed much lower household demand, particularly with respect to irrigation consumption (Figure 2). This could be due to the recent water restrictions in the region combining with a range of other factors to reduce irrigation demand (e.g. larger homes on smaller lot sizes, working families, etc.). Other recent studies (e.g. Beal et al. 2011) also showed low irrigation consumption confirming the downward trend in irrigation demand compared to the historical norm.

\section{[INSERT TABLE 1]}

\section{[INSERT FIGURE 2]}

In most of the developed world, water conservation measures are being mandated for new residential and commercial developments as well as refurbishments (Micou et al. 2012). Such efforts are driving down indoor water consumption (e.g. Willis et al. 2011a) and the associated daily peak morning and afternoon consumption periods (e.g. Carragher et al. 
2012). Urban water consumption in most States of Australia has been declining over the past 10 years because of restrictions, water saving devices and consumer education associated with a long and severe drought restrictions (Willis et al. 2010; Willis et al. 2011a). This is reflected in the lower than historical overall consumption value for the Gold Coast City study (Willis et al. 2009), although the volume of consumption associated with most indoor end use types remains relatively constant except for irrigation and leaks. Undoubtedly, better understanding of irrigation water demand and its contribution to peak demand in a city is essential to better understand means to more efficiently manage pipe network infrastructure (Taylor, 2012).

\subsubsection{Disaggregating longitudinal hourly data}

Water end use studies are resource intensive so they typically only cover average day demand in seasonal periods and rarely indicate end use contributions to peak hour or peak day demand. However, longitudinal rather than snap-shot data often applied for end use studies is essential to reveal peak demand trends, and the advent of hourly data for a large number of dwellings over such extended periods, as available to this research study, allows for greater understanding on the determinants of peak demand (Stewart et al. 2010). This study seeks to develop an alternative approach to categorising water use, particularly making distinctions between indoor and outdoor use, for the purpose of understanding the end use consumption (particularly irrigation) determinants (e.g. property size, season, etc.) of peak hour, day and monthly consumption. While the proposed approach will not provide the level of disaggregation accuracy achieved by end use studies enabled by costly higher resolution meters, it can be feasibly applied to the affordable current generation smart meters (i.e. lower resolution recording such as $1 \mathrm{hr}$ ) which are more widespread internationally (e.g. city of Hervey Bay) and has far less requirements for exhaustive analysis. 


\section{Research objectives and scope}

This study aims to provide accurate estimates of the outdoor and indoor components of peak hour, peak day and peak month residential water use.

\subsection{Research objectives}

The specific research objectives are:

1. Identify the proportion of indoor and outdoor residential consumption and the likely underlying end uses of this consumption.

2. Identify the major causes (e.g. temperature, lot size, dwelling type, etc.) of significant fluctuations (i.e. peak demand periods) in residential consumption.

3. Measure the end use volumes occurring during peak demand periods and identify the variations in end use volumes which cause peaks in demand.

\subsection{Research scope}

The study is based on the analysis of the hourly consumption data of 2,884 dwellings recorded during the period $1^{\text {st }}$ July 2008 to $30^{\text {th }}$ June 2009 . The study scope is limited to:

1. Comparing residential consumption by property size and dwelling type. It was with this purpose in mind that the study sample $(2,884)$ was selected by DMA as property size is usually consistent within each DMA.

2. Examining seasonal fluctuations in consumption and determining the effect of temperature and rainfall on residential consumption.

3. Analysing peak hour, peak day and peak month residential consumption to determine the causes of peak demand. 
4. Discussing the implications of the research findings in relations to their benefits to urban water planning and management.

\section{Method}

\subsection{Overview}

The research study applied a number of key research stages that were completed in order to achieve the outlined objectives. These are briefly described below and outlined in detail in subsequent sections:

1. Study dataset collation from city smart meter fleet database;

2. Development of method for disaggregating hourly consumption data;

3. Identifying the determinants of increased urban water demand;

4. Identifying the causes of peak urban water demand; and

5. Study implications assessment for urban water planning, practice and policy.

\subsection{Urban water dataset and study context}

\subsubsection{Sample selection}

The selection criteria for the residential connections included in the study (i.e. study sample) were based on District Metered Areas (DMA) that had demographic and socio-economic characteristics that were representative of the entire city of Hervey Bay. Hervey Bay is a widely spread city having 55,000 inhabitants situated in Queensland, Australia. The city is situated approximately $290 \mathrm{~km}$ north of the state capital, Brisbane. The city is dependent on tourism for its primary economic base. It also has a small light industrial base, centred in the 
suburb of Urangan, however, the vast majority of commercial consumers are engaged in the service industries associated with tourism.

Within the city, the overwhelming majority of water connections serve residential properties. Of the approximate 23,000 connections (as of 1 July 2008), less than four per cent are commercial connections. The remaining connections are residential connections. Importantly, residential growth has centred on the immediate urban environment and encompasses the majority of the residences in the study; however significant development has occurred in outlying seaside suburbs, such as Dundowran, Toogoom and Burrum Heads in the north, and Turtle Cove and River Heads to the south. These outlying suburbs often have property sizes greater than $1,000 \mathrm{~m}^{2}$ and, to obtain a more representative sample, one DMA, encompassing this type of residential sub-division, was included. The following DMAs were selected:

- One residential city DMA - (DMA 21);

- One residential DMA outer suburb with larger average block sizes (DMA 10);

- One DMA with mixed residential and commercial consumers (DMA4); and

- $\quad$ One small DMA which has the highest ratio of commercial connections (DMA 36).

Importantly, this DMA selection process provided diversity in residential property size, as most residential properties are of similar size within the DMAs. Table 2 shows the total number of residential connections within the selected DMAs included in the study and the average single residential block size.

[INSERT TABLE 2] 


\subsubsection{Capturing and logging data}

The water consumption profile data was made up of a series of readings from a water meter that automatically logged and stored information at a set interval. These intervals may range from every second, right up to days or weeks, depending on the capability of the automated reading system. These readings, when taken as a series over a period of time, provide a profile or pattern of individual consumer water usage. The consumption data used for this research was recorded at hourly intervals.

Many types of water meters communicate with data loggers via a magnetic pulse which is peoduced every time a set volume of water passes through the meter. Smaller 20 and $25 \mathrm{~mm}$ meters, used on residences, commonly pulse at every five litres. Larger meters, which are capable of recording high volume flows, may only produce a pulse for every $100 \mathrm{~L}$ (or even $1000 \mathrm{~L}$, in the case of much larger meters).

Meter size has important implications for analysing hourly profile data where the highest resolution produced is $100 \mathrm{~L}$. Hence, these meters are not suitable for the hourly consumption analysis used to estimate the usage types. For this reason, only data from the $20 \mathrm{~mm}$ meters with 5 litres per pulse output servicing individual single and multi-residential occupancies were included in the study. As a final note, connections showing zero consumption in the recording period were excluded.

\subsubsection{Environmental conditions during the data collection period}

The period of data collection spanned the year $1^{\text {st }}$ July 2008 to $30^{\text {th }}$ June 2009. This financial year was selected because it was the latest period for which data was available and there were no water restrictions in place to distort results. Comparing this year to the previous 4 years (Table 3) for the whole of Hervey Bay shows that the influences of rainfall and temperature 
variations on key analysis parameters such as max day consumption were not critical in the year the study data was recorded. Consumption on the max day was only 1.19 ML or 5.65\% less than the average for the 5 year period.

\section{[INSERT TABLE 3]}

Table 4 represents a comparison of the hottest 5 months of the year in Hervey Bay over the same 5 year period. The max day in Table 4 represents an average of the day of highest consumption in each of the 5 months and is sorted in ascending order. Rainfall is averaged over these hottest 5 months in each year as is the maximum daily temperature. It is noticeable that there is no simple correlation between the volume of max day consumption and temperature. Table 3 showed that the rainfall in December 2008/09 was the lowest of the 5 years and the max day volume during 2008/09 was the 2nd lowest indicating that there is no obvious relationship between rainfall and max day consumption volume. However, there does appear to be a trend that higher rainfall results in a decrease in max day consumption due likely to lower requirements to irrigate lawns.

\section{[INSERT TABLE 4]}

The average of the November/March rainfall over the 5 year period was $109 \mathrm{~mm}$ and the average monthly rainfall for the November/March period in study year of 2008/09 was only 6\% higher. Temperature differences were similarly insignificant with average daily maximum temperature during the November/March months over the 5 year period being $29.4^{\circ} \mathrm{C}$ while the average recorded during the November/March 2008/09 study period as $29.5^{\circ} \mathrm{C}$. This comparative assessment demonstrates that the $2008 / 09$ sampling period was very much an average year as far as summer rainfall and temperature is concerned. As a final 
note, there is evidence that the consumption volume on max day each year is influenced by the average rainfall falling over the whole summer period and not by the amount of rainfall experienced in the month in which max day occurred.

\subsection{Method for disaggregating hourly consumption data}

The following steps provide a method of disaggregating hourly consumption data into proportions of water end uses

\subsubsection{Step 1: Disaggregation design formulation}

Water consumption may be defined by usage type such as flushing toilets, showering, cooking and watering the lawn; these are all components of water use. Early morning consumption (12:00 am to 5:00 am) is predominantly made up of hourly consumption volumes of less than $10 \mathrm{~L}$. The usage of larger volumes increases approaching the peak demand periods.

From hourly consumption volumes, it is possible to assume various usage types. For example, a recorded volume of $10 \mathrm{~L}$ in an hour has several likely uses such as a toilet flush, hand washing, cooking, drinking or making a cup of tea, which are the type of use either singularly or in combination that could account for $10 \mathrm{~L}$. On the other hand, it gets more difficult if the volume was $100 \mathrm{~L}$ in one hour as all these potential uses plus others may contribute.

An hourly consumption figure of $1,200 \mathrm{~L}$ may be assumed to be predominantly outdoor consumption as the total flow through the meter must have been at a minimum flow rate of $1,200 \mathrm{~L} / \mathrm{hr}$ (the tap may also have been running at 2,400 L /hr for 30 minutes). Profile data is 
simply a volume recorded for each hour in $10 \mathrm{~L}$ increments (i.e. 10, 20, 30, $40 \mathrm{~L}$ etc.); the range starts at $10 \mathrm{~L}$ and goes up to whatever volume the network pressure and flow allow through a $20 \mathrm{~mm}$ residential connection. Initially, the total consumption of all 2,884 residences was analysed according to 29 volume ranges which shows for example, that 8.14\% of all consumption occurred in volumes equal to or less than $10 \mathrm{~L} / \mathrm{hr}$ (see Figure 4). However, there is little benefit in applying a resolution increment of $10 \mathrm{~L}$ to volumes above $100 \mathrm{~L}$ since a recorded consumption volume of $130 \mathrm{~L}$ will indicate no more about the likely combinations of end usage type than $140 \mathrm{~L}$.

\subsubsection{Step 2: Understanding typical hourly water usage profiles}

The next step involved ranking the consumption by volume range and time. Table 5 shows the average hourly consumption ranges, ranked by volume, and also shows a possible mix of usage types or purposes. So the highest consumption volume between 12.00 am and $1.00 \mathrm{am}$ was $10 \mathrm{~L}$. The second highest consumption volume during the same hour was $20 \mathrm{~L}$ and the third highest was $30 \mathrm{~L}$.

\section{[INSERT TABLE 5]}

The full profile of consumption ranges during four selected hours, averaged over the whole study period, is shown in Figure 3. This figure shows how the profile of hourly consumption changes throughout the day. The noticable peaks during three of the four hours represent consumption volumes in the ranges $>100<=120$ and $>200<=250 \mathrm{~L} / \mathrm{hr}$. The hours with the highest peaks, 8.00 am to 9.00 am and $6.00 \mathrm{pm}$ to $7.00 \mathrm{pm}$ are the peak periods of the day. Consumption during the early morning hour of 3.00 am to 4.00 am is noticably flat with the largest volume in the $10 \mathrm{~L}$ range. 


\section{[INSERT FIGURE 3]}

The contribution that each volume range makes to the total volume of average hourly consumption for the average day of the study period was determined (Figure 4). The peaks in the ranges $>100<=120 \mathrm{~L} / \mathrm{hr}$ and $>200<=250 \mathrm{~L} / \mathrm{hr}$ are evident in most hours of the day though this does not mean that these flow ranges have the highest total volumes. Consumption in the $10 \mathrm{~L}$ range, for example, is consistently high for every hour and thus has the highest total volume for all ranges.

\subsubsection{Step 3: Proportioning consumption in volume ranges}

Figure 4 shows a breakdown of consumption by volume range as a percentage of total consumption for all 2,884 residential connections in the study for the year $1^{\text {st }}$ July 2008 until $30^{\text {th }}$ June 2009. This shows the contribution each volume range makes to total consumption.

There are five distinct sections which may indicate a change in usage type or more likely an aggregation of a greater number of usage types. These sections are the hourly usage volumes from 10 to $100 \mathrm{~L},>100<=250 \mathrm{~L},>250<=600 \mathrm{~L}$, and $>1200 \mathrm{~L} / \mathrm{hr}$. Consumption volumes increase at the begininng of each section and then tail away until the beginning of the next group of consumption ranges.

\section{[INSERT FIGURE 4]}

A recorded volume of $300 \mathrm{~L}$ in one hour could, based on the Willis et al. (2009) findings for a residence with an EP of 2.5, account for all typical indoor uses. It may be assumed that the 
average household would not often use more than $300 \mathrm{~L}$ indoors in one hour i.e. on average a houshold using more than $300 \mathrm{~L}$ in one hour would be using at least some for outdoor purposes such as irrigation. For usage volumes greater than $600 \mathrm{~L} / \mathrm{hr}$ the assumption would be that most would be outdoor consumption. This assumption is further supported by the breakdown of consumption shown in Figure 5 which further consolidates all volumes into just four ranges.

\section{[INSERT FIGURE 5]}

\subsubsection{Step 4: Deducing typical consumption uses in four volumetric ranges}

Clearly the $300 \mathrm{~L} / \mathrm{hr}$ mark is the point above which usage dramatically decreases. Consumption in volumes $<=300 \mathrm{~L} / \mathrm{hr}$ totals $78.65 \%$ of all consumption. A high proportion of the remaining $21.35 \%$ of consumption, i.e. consumption in volumes greater than $300 \mathrm{~L} / \mathrm{hr}$, would typically be outdoor consumption.

It makes sense therefore to analyse the consumption data by the four volumes ranges shown in Figure 5. It follows that we can then estimate the usage volumes for outdoor and indoor consumption during peak demand periods keeping in mind that no assumption about usage type can be based on absolute certainty since consumption in any hour potentially comprises every usage type for any given volume as shown in Table 63.

[INSERT TABLE 63]

The components in Table 63 are ranked according to assumptions on probability. Usage between 300 and $600 \mathrm{~L} / \mathrm{hr}$ may be composed of all possible types of usage but on average the 
likelihood is that outdoor consumption contributes significantly to this range and will be the dominant contribution in the $>600 \mathrm{~L} / \mathrm{hr}$ range.

These assumptions may be tested in two ways; first, on the premise that all consumers contribute to the indoor components of water usage but a much smaller proportion contribute to the higher volume ranges. Following on from this premise, a reasonable assumption is that those consumers who make little or no contribution to the higher volume ranges have consumption patterns typifying indoor usage.

An analysis of the consumption of the 390 multi-residential connections in the study shows that $90.5 \%$ of consumption occurs at volumes $<=300 \mathrm{~L} / \mathrm{hr}$. The fact that these types of dwelling usually have little or no garden provides some certainty that their consumption patterns do typify indoor usage.

\subsection{Identifying the determinants of increased urban water demand at peak periods}

It was important to estimate threshold levels of hourly consumption indicating outdoor consumption taking place. This threshold level was based on evidence provided from this study along with prior recorded values for indoor use gained from recent end use studies using high resolution loggers. Values of around 340 litres per household per day (L/hh/d) indoor demand and associated end use diurnal demand patterns were available (e.g. Willis et al. 2009). If more than $300 \mathrm{~L}$ was used in one hour (i.e. almost as much as the average indoor consumption for one day), then deductively the likely purpose of this consumption above the threshold was for outdoor consumption. Identifying average volumes for different indoor purposes and appliances is another way of identifying a split between indoor and outdoor consumption during an hourly period. Also looking at the typical daily and hourly 
consumption of multi-residential properties showed very little consumption above $300 \mathrm{~L} / \mathrm{hr}$. This property type helped to establish typical volume consumption thresholds for daily indoor and outdoor water use. Identifying the causes of peak hour, day and monthly demand could be determined from this method.

\subsection{Study implications assessment for urban water planning, practice and policy}

Managing peak demand is a central tenet of efficient water supply planning over various planning horizons. Peak demand directly influences infrastructure design criteria and thus has a cost which various peak industry bodies have attempted to identify. Once results were produced from the data analysis process, a series of interviews with senior engineers, academics, and urban water planners were conducted in order to establish support for a range of key implications of smart metering for urban water planning, practice and policy.

\section{Data analysis and results}

\subsection{Identifying the determinants of increased urban water demand}

This section includes analysis of consumption by property type and size, examines the influence of season on water consumption and provides a detailed breakdown of hourly use by volume for the peak hour, peak day and peak month. In this way the proportionate use of water for outdoor purposes can be better understood and its influence on fluctuations in residential consumption volumes can be determined.

\subsubsection{Influence of property size/type}

The analysis included a comparison by property type and by DMA to quantify the relationship between consumption and property size and type. Note that only single 
residential consumption is broken down by DMA. All multi-residential connections are treated as a distinct group.

DMA 36 (Figure 6) with the smallest average property size is notable for the very small proportion of usage in volumes $>300 \mathrm{~L} / \mathrm{hr}$ and a consumption profile similar to the multiresidential properties. Figure 6 graphically illustrates the small contribution high-volume consumption makes to overall consumption in DMA 36.

\section{[INSERT FIGURE 6]}

The existence of a relationship between property size and consumption $>300 \mathrm{~L} / \mathrm{hr}$ is further supported by the diurnal pattern for multi-residential water use displayed in Figure 7. Most consumption by multi-residential property types occurs primarily in volumes $<300 \mathrm{~L} / \mathrm{hr}$ with very little water use in volumes $>300 \mathrm{~L} / \mathrm{hr}$.

\section{[INSERT FIGURE 7]}

The peaks for volumes over $600 \mathrm{~L} / \mathrm{hr}$ in Figure 7 are in fact each the regular contribution of single users. Table 7 shows each consumption volume range as a percentage of total consumption by DMA and multi-residential customers, and highlights the greater use at volumes $>300$ L per hour for the DMAs with larger block sizes. DMA 10 with the largest average property size has the highest proportion of usage in both the $>300<=600$ and $>600$ L/hr range. 
Consumption by multi-residential customers (along with the single residences in DMA 36) may provide a typical average daily diurnal pattern of indoor domestic usage for residential connections in Hervey Bay, Australia as we can be certain it contains only a very small proportion of outdoor use. This assumption is supported by the consumption comparison in L/connection for each volume range.

DMA 36 single residential and all multi-residential consumption is noticably less at all ranges though proportionately much less at volume ranges $>300 \mathrm{~L} /$ hour. Differences in the $<=300$ L/hr range may be because a higher proportion are holiday units which are not continually occupied. Both multi-residential dwellings and those in DMA 36 on the sea front are more likely to have a higher proportion of holiday rentals.

A relationship between property type and consumption at higher volumes $>300 \mathrm{~L} / \mathrm{hr}$ seems clear as multi-residential dwellings have lower consumption at all ranges and a much smaller proportion of outdoor consumption.

\section{[INSERT TABLE 7]}

The analysis has shown a relationship between increased high-volume hourly consumption and property size; the fact that small properties use very little water at rates $>300 \mathrm{~L} / \mathrm{hr}$ also supports the hypothesis that the indoor usage of small properties and multi-residential dwellings typify indoor consumption profiles.

Overall, there is enough evidence to support the assumption that on average most water use at $<=300 \mathrm{~L} / \mathrm{hr}$ is for indoor purposes for both residential property types; but the data does not 
indicate with a high degree of certainty about usage types for any specific volume at any given time.

\subsubsection{Seasonal influences}

It is widely known that climatic variations due to changes in the seasons influence residential consumption (e.g. Polebitski and Palmer, 2010). Outdoor consumption is significantly more affected by variations in rainfall and temperature than indoor consumption due to the effect on evapo-transpiration from gardens and lawns. The consumption patterns of the residential connetions in this study support this view.

Maximum monthly peak hour volumes by property type are given in Table 8 . Note that all property types were analysed individually and the monthly peak hours for each category did not necessarily fall on the same day. This is the reason why the sum of the single residential and multi-residential figures is not equal to the all residential figure which, as an aggregate of all residential consumption, had a peak hour that fell on a different day.

Again, the influence of outdoor water use is implicit in the comparison of water use by property type during summer and winter months. The total multi-residential consumption for June is actually more than for December whereas the single residential consumption for December is $204.5 \%$ higher than for June.

\section{[INSERT TABLE 8]}

Figure 8 illustrates the seasonal pattern for peak demand. A dramatic rise in single residential consumption during the summer months is clearly contrasted with multi-residential and 
commercial consumption; neither of which are significantly affected by season. The decline in commercial consumption during June/July is due to the drop in tourist numbers during the winter off-peak season.

\section{[INSERT FIGURE 8]}

Figure 9 confirms the seasonal effect on various consumption volume ranges for the single residential property type in DMA 21, which is one of the DMAs with high levels of outdoor consumption. The graph illustrates the seasonal effect on each volume range and clearly show the the rise during summer for consumption greater than $300 \mathrm{~L} / \mathrm{hr}$. In the sub-tropical Hervey Bay region, outdoor usage is the only logical usage type that could be significantly affected by season.

\section{[INSERT FIGURE 9]}

Table 9 provides another perspective to seasonal variations in consumption by showing monthly peak hour consumption as a percentage of the peak hour in December. July's peak hour consumption for example was $56.16 \%$ of the annual peak hour consumption.

\section{[INSERT TABLE 9]}

Why do consumers use more water outdoors during summer? It seems counter-intuitive as average rainfall in Hervey Bay is generally highest during the summer and autumn months. However, examination of longer term weather records indicates that in non-drought conditions in a sub-tropical city such as Hervey Bay, temperature, not rainfall, is the cause of 
seasonal variations in outdoor consumption (Figure 10). This relationship evident in this study has also been well established by water demand forecasting studies in the literature (e.g. Wilby and Miller, 2009).

\section{[INSERT FIGURE 10]}

Temperature and monthly peak demand are definitely in synchrony in Figure 10; but as illustrated in Figure 11 there is no such conformity between long term rainfall and consumption patterns in non-drought conditions.

\section{[INSERT FIGURE 11]}

Rainfall certainly has a significant short term effect usually measured in days; but it seems to have no discernible long term influence on consumption in Hervey Bay other than an irregular coincidence of consumption peaks and rainfall peaks which show higher consumption and higher rainfall in summer months. This indicates that the higher rainfall during summer is usually also offset by higher temperatures and the associated consumption increases to peak demand.

The period indicated by lower rainfall figures between months 18 and 30 on the x-axis in Figure 11 was a drought period. Monthly peak hour consumption actually rose during this time, so the restrictions in place at this time appear to have not had the desired effect on capping demand. 
The above analysis provides solid evidence that outdoor usage is the cause of the increase in residential consumption during the summer months.

\subsection{Identifying the causes of peak urban water demand}

This section examines peak water demand during the period 1 July 2008 to 30 June 2009. Peak hour demand occurred on 29 December 2008 between 7:00 pm and 8:00 pm and peak day demand, not surprisingly, occurred on the same date. Peak month demand reflected the seasonal influence on residential consumption and roughly correlates to the month of December.

By comparing peak hour with average day peak hour, peak day with minimum day and peak month with minimum month the variations in indoor and outdoor consumption are highlighted and the end uses contributing most to peak demand substantiated.

\subsubsection{Yearly peak hour compared to average day peak hour demand}

Table 10 shows the total volume of consumption by property type during this hour compared to the average morning and peak hour consumption. This comparison illustrates the difference in scale of annual peak hour consumption.

\section{[INSERT TABLE 10]}

Average evening peak hour consumption and annual peak hour consumption by volume range for both property types is given in Table 11. This table clearly highlights the volume ranges where single residential consumption increased during the annual peak hour. 
[INSERT TABLE 11]

By far the greatest increase was in volumes that could be attributed directly to outdoor use (i.e. consumption volumes $>600 \mathrm{~L} / \mathrm{hr}$ ) which accounts for $44.31 \%$ of total single residential peak hour consumption. If a large proportion of volumes above $300 \mathrm{~L} / \mathrm{hr}$ are also considered to be mainly outdoor use then almost two thirds of single residential peak hour consumption could be attributed to outdoor use.

\subsubsection{Peak hour demand}

Only a very small percentage of consumers regularly use water at volumes greater than $300 \mathrm{~L}$ per hour. Of a total of 2,884 residential connections, 235 connections used water in volumes $>300 \mathrm{~L}$ during the peak hour and only 106 (just 3.67\%) registered consumption >600 L during the peak hour.

Even during peak hour most customers used water at low volumes and a surprisingly high number, $36.21 \%$ of single residential customers and 53.59\% of multi-residential customers, did not use water at all during the peak hour. This may be because people were away over the Christmas break, or units were vacant or simply because many were using water during other hours.

[INSERT TABLE 12]

Just over half (53.64\%) of all residential connections used water solely for indoor purposes ( $<=300 \mathrm{~L}$ ) during the peak hour and the average volume used by these connections was 
similar across all property sizes. Table 13 shows the peak hour consumption per connection for all volume ranges represented by single residential/DMA and multi-residential categories, calculated using only those connections recording consumption during the annual peak hour. The variation between residential classification categories for average usage within the 10 to $100 \mathrm{~L}$ per hour range does not exceed 3.64 L and the variation over the range from 101 to 300 L per hour was only $31.92 \mathrm{~L}$.

[INSERT TABLE 13]

The relatively small variation between values in the lower volume consumption ranges (i.e. $=<300 \mathrm{~L} / \mathrm{hr}$ ) across the different residential property types and sizes gives further confidence that this consumption was for similar purposes indoors. More importantly, the analysis showed that outdoor consumption is mostly responsible for the increase in the volume of peak hour demand relative to normal average daily peak demand.

\subsubsection{Peak day demand}

The peak day in the study period was that which had the highest volume of consumption recorded and fell on the same date as the peak hour, namely, 29 December 2008. The day on which consumption was lowest was 19 May 2009. Consumption on this day (i.e. $958.36 \mathrm{~kL}$ ) was only $40 \%$ of the volume supplied to consumers on the peak day (i.e. 2,384.8 kL).

Average daily consumption totalled $1,410 \mathrm{~kL}$ so peak day consumption was 2.5 times minimum day consumption and 1.69 times average day consumption. Table 14 compares peak day consumption with the minimum day consumption with the intention of highlighting 
the influence of outdoor consumption as it is assumed that the level of indoor consumption should remain consistent throughout the year.

Of the 2,884 residential connections in the study, 2,334 recorded some consumption on the minimum day and 2,457 connections recorded consumption on the peak day. But the small difference of 123 additional connections using water on the peak day does not account for the much greater variation between consumption for these two days.

\section{[INSERT TABLE 14]}

The greatest difference was both in the volume of outdoor usage and the number of customers using water outdoors. Not only did more residences use water outdoors, they used it for longer periods with the average usage on peak day for the range $>300<=600 \mathrm{~L} / \mathrm{hr}$ range almost $120 \mathrm{~L}$ per connection higher. Average usage volume in the range $>600 \mathrm{~L} / \mathrm{hr}$ on the peak day was much higher at 2,186.8 L compared to 1,492.4 on the minimum day (Table 15).

In terms of volume, the comparison showed that for the volume range $10<=100 \mathrm{~L} / \mathrm{hr}$ there was just under a $15 \%$ increase that was probably associated with predominantly personal use such as hygiene, cooking and drinking. The volume of use in the range from 100 to $300 \mathrm{~L} / \mathrm{hr}$ doubled which can be probably attributed to a greater number of water end use events such as showering and clothes washing.

[INSERT TABLE 15] 
When comparing the volume of consumption in the $>300 \mathrm{~L} / \mathrm{hr}$ category, their exists a 1,085.4 kL volume on the peak day compared to just $63.6 \mathrm{~kL}$ on the minimum day, which provides robust evidence that irrigation was likely to be the predominant contributor to peak demand on the 29 December 2008 (i.e. peak day). In summary, for this study sample group and the study period examined, the above analysis provides strong evidence to demonstrate that the peak day was largely caused by residential outdoor use.

\subsubsection{Peak month demand}

Basing "peak month" on calender months may reveal the calender month with the largest consumption volume but it won't locate the one-month period where consumption is highest. That is why water utility engineers use a rolling 30 day average to define peak month which they refer to as "Max Month". For this sample population and examined 12 month study period, the rolling 30 day duration that represented the peak month extended from 3 December 2008 until 1 January 2009 inclusive.

Again, to see why "max month" stands out we compare it to the month with minimum consumption and note the differences. The lowest rolling 30 day average consumption (Min Month) occurred between 19 May 2009 and the 17 June 2009 inclusive. Table 16 shows the number of connections recording consumption and per connection consumption during Max and Min months.

[INSERT TABLE 16]

As established previously with peak hour and peak day consumption it is the increase in outdoor consumption that differentiates Max Month. When comparing consumption per 
connection in each period, indoor consumption $<=300 \mathrm{~L} / \mathrm{hr}$ remained remarkably consistent while outdoor consumption increased by over $600 \%$. Consumption in volumes $>600 \mathrm{~L} / \mathrm{hr}$ increased by almost $800 \%$. It is interesting to note that the number of customers using water outdoors during Max Month only increased by 234\%. This indicates that customers using water outdoors also watered much more often during the peak month.

\section{Conclusions}

\subsection{Identifying outdoor and indoor consumption}

It is possible to identify indoor and outdoor consumption with an acceptable degree of accuracy using hourly consumption data. There is a consistency of consumption in volumes $<=300 \mathrm{~L} / \mathrm{hr}$ between DMAs with large property sizes and multi-residential properties which denotes this volume as a threshold for indoor water use. Hourly volumes above this threshold are on average for outdoor purposes. The lack of a seasonal effect on consumption volumes $<=300 \mathrm{~L} / \mathrm{hr}$ and the contrasting, very clear effect that season has on consumption $>300 \mathrm{~L} / \mathrm{hr}$ during peak hour, peak day and peak month provides further confirmation.

\subsection{The relationship between consumption and property size/type}

Property size was determined as a significant influencing factor on residential consumption and there is a clear relationship between larger property size and increased outdoor consumption. Properties in excess of $3,000 \mathrm{~m}^{2}$ showed the highest level of outdoor use by proportion and volume. Smaller properties of around $500 \mathrm{~m}^{2}$ and multi-residential dwellings showed consistently low levels of outdoor water use; their consumption patterns typified indoor usage and are consistent with usage patterns of the larger sized properties at volumes $<300 \mathrm{~L} / \mathrm{hr}$. 


\subsection{Seasonal influences on consumption}

By far the most influential factor causing flucuations in residential consumption is the season and specifically temperature. Monthly peak hour single residential consumption in December 2008 was $204.5 \%$ higher than for June 2008. In contrast, the multi-residential consumption for June was higher than for December. The influence of outdoor consumption was implicit in the overall increase in residential consumption during the summer season when compared to the winter season.

The analysis also showed that the dramatic increases in consumption during peak hour, peak day and peak month are caused by increases in outdoor consumption which is influenced by variations in temperature and rainfall. This influence is heightened when temperature and rainfall mutually reinforce each other; such as when high temperatures and low rainfall trigger the highest levels of outdoor consumption while low temperatures and high rainfall will reduce outdoor consumption.

\subsection{Peak hour consumption}

By far the greatest increase in peak hour consumption was in volumes that could only be attributed directly to outdoor use (i.e. consumption volumes $>600 \mathrm{~L} / \mathrm{hr}$ ) which accounts for $44.31 \%$ of total single residential peak hour consumption. If volumes above $300 \mathrm{~L} / \mathrm{hr}$ are assumed to be predominantly outdoor use then the contribution by outdoor use to single residential peak hour consumption could be as high as two thirds. Only 225 out of a total of 2,884 consumers recorded consumption $>300 \mathrm{~L} / \mathrm{hr}$ during the peak hour; so a small proportion of residential consumers, less than $10 \%$, were thus responsible for $66.35 \%$ of 
residential peak hour consumption. This consumption was predominately for outdoor purposes.

\subsection{Peak day consumption}

A comparison of peak day with minimum day consumption showed that outdoor consumption accounted for most of the increase on peak day with a significant increase in both the volume of outdoor usage and the number of customers using water outdoors. Not only did more residences use water outdoors, they used it more often or in higher volumes.

\subsection{Peak month consumption}

It was the increase in outdoor consumption that also differentiated peak month from minimum month. When comparing consumption per connection in each period there was remarkably little variation in consumption $<=300 \mathrm{~L} / \mathrm{hr}$ while consumption $>300 \mathrm{~L} / \mathrm{hr}$ increased by over $600 \%$. Consumption in volumes $>600 \mathrm{~L} / \mathrm{hr}$ increased by almost $800 \%$. The number of customers using water outdoors during the peak month only increased by $234 \%$ indicating that customers using water outdoors also watered much more often during peak month.

\subsection{Considerations for different levels of commercial consumption}

Figure 12 illustrates the average hourly consumption for the original study group which included 269 commercial connections as well as the 2,884 residential connections included in this research study. Readers should note that the ratio of residential to commercial connections included in this study sample is representative of the greater Hervey Bay region. 
Since residential consumption is the largest component of total demand it creates the twin distinct morning and afternoon peaks that are commonly associated with diurnal water consumption patterns. Behaving differently to residential consumption, commercial consumption rises to a peak around midday and tails off before the evening residential peak hour. For most water utilities, residential consumption is invariably the largest component of overall consumption so generally forms the familiar twin peaks of the diurnal pattern that represents average daily consumption. However, there are some water supply areas or even cities/towns where the commercial proportion may be much higher thereby changing the shape of the diurnal pattern. For the Wide Way Water Corporation jurisdiction in which this study was conducted, $18.4 \%$ of consumption was derived from commercial customers. However, this proportion can flucuate from one water utility to another, such as in Sydney Water (28\%), Brisbane Water (33.6\%) and Yarra Valley Water (21.6\% ) (NWC, 2009/10). Nonetheless, even with a higher proportion of commercial consumption in a region, the daily variability in residential consumption will still be dominant due to the much lower variability in commercial consumption.

\subsection{Summary}

A summary of the key findings of the study are summarised as follows:

- Smart meters with hourly recording intervals can be utilised to reliably determine the degree of outdoor consumption within a water supply network;

- Larger sized residential properties $\left(>3,000 \mathrm{~m}^{2}\right)$ had significantly more demand in higher consumption ranges (e.g. $>300 \mathrm{~L} / \mathrm{hr}$ ) than the typical $500 \mathrm{~m}^{2}$ lot indicating much higher irrigation occuring at these properties in order to maintain their more expansive gardens; 
- Season and specifically temperature were the significant predictors of heigthened residential consumption with the peak hour demand in the summer months being approximately double that of winter;

- The combination of sustained high temperatures and low rainfall significantly heightened comsumption due to an exponential increase in irrigation demand;

- Irrigation contributed to over 40 percent of total residential peak hour consumption;

- Only 10 percent of customers were responsible for two thirds of this peak hour consumption due to their very high outdoor usage;

- Outdoor consumption accounted for the majority of peak day consumption with both an increase in volume for outdoor usage as well as the number of customers using water outdoors; and

- In the peak month where average temperatures were higher, there was a significant increase in irigation consumption (6-8 times) and noticibly more customers being inclined to irrigate their lawns.

\section{Study implications to urban water planning and management practices}

\subsection{Urban water infrastructure planning}

The ability to measure the outdoor component of domestic water use can be valuable to infrastructure planning and design. As this study has shown, it is outdoor consumption that causes the much higher levels of consumption during peak hour, peak day and peak month and being able to reduce this load on the supply system may have some benefits.

Better management of peak hour demand may not return the desired level of benefits that are often touted for the simple reason that the provision of fire-fighting capacity limits the 
reductions achievable. However, reducing consumption on peak day and during peak month would have definite benefits as the peak consumption in these periods are the dominant parameters for infrastructure design and sizing of the most expensive components of water supply systems, such as, treatment plants, reservoirs and trunk mains. Any deferment of augmentation of these types of assets would provide significant financial benefits.

Hydraulic models also benefit from the availability of an extensive set of hourly consumption data by tweaking various diurnal patterns using actual hourly consumption data for different end use types, particularly commercial use which is notoriously difficult to estimate. This can make models more accurate and efficient.

Planning engineers can use hourly consumption data to confirm their estimates of both “Equivalent Dwelling” (ED) and "Equivalent Persons” (EP) consumption which are also significant design parameters throughout the water supply system. Overestimates of these parameters often results in oversized infrastructure.

Correct sizing and selection of customer meters can also be enhanced by the availability of hourly consumption data. This particularly applies to the metering of commercial and industrial premises where flow rates vary significantly over each 24 hour period. Meters should be sized and selected on the basis of their diurnal pattern.

There are also benefits from hourly consumption data in wastewater collection systems where estimates of average dry weather flow, which is another important design criterion, can be cross checked against indoor consumption in sewer catchments. Similarly estimates of inflow 
and infiltration into the system can be enhanced by cross checking hourly wastewater flows with hourly consumption.

\subsection{Alternative tariff structures}

Pricing signals are another method of reducing peak demand using an hourly inclining block tariff that is designed to apply a "peak hour charge" to consumption above a certain threshold on an hourly basis. Cole (2011) provides a recent assessment on the feasibility and potential structure of time of use tariffs using hourly consumption information sources.

Pricing signals based on a seasonally adjusted tariff could also be used to achieve a reduction in outdoor demand on the peak day and during the peak month. A scarcity or seasonal tariff could be structured similar to the peak tariff described above with a penalty charge applying to all consumption above a certain hourly threshold. This could be adjusted to apply to outdoor consumption during all hours of the day, thus reducing the overall level of demand.

\subsection{More effective demand management strategies}

Accurate measurement of indoor consumption for the whole customer base will allow better estimates on the efficiency of water education strategies, efficient water appliance programs, post-meter leakage reduction programs and other tailored initiatives to promote water conservation where required.

Identifying the diurnal patterns of the largest commercial users may allow the application of specific tariffs such as time-of-use for individual consumers. From the perspective of managing peak hour consumption, greater knowledge of likely water end use consumption (i.e. shower, toilets, etc.) allows the application of non-pricing methods to reduce peak hour 
demand. Water restrictions applied on alternate days (i.e odd and even lots) may significantly reduce peak hour outdoor consumption as would a total ban on outdoor water between the hours of 8.00 am and $8.00 \mathrm{pm}$. The herein analysis methods could also be applied to achieve reductions in peak day and peak month consumption. Hourly consumption data would indicate both the changes in customer usage patterns and the effectiveness of these type of restrictions.

Of course this data also allows the identification of all customers who breach water restrictions. Much of the ill-feeling generated by consumers 'dobbing' in others during periods of water restriction would be negated. Customers would know that as a matter of course that breaches of water restrictions would be identified directly by the water authority and appropriate fines issued.

The ability to measure outdoor and indoor consumption not only contributes to the design of all these types of demand management programs but also provides the tool to accurately monitor the results.

\subsection{Customer service}

Every water utility essentially has the same aim for customer service; to supply potable water of a suitable and consistent quality at minimum social, financial and environmental cost. The same can be said of watewater collection and disposal. All of the benefits described above contribute to this aim so also contribute to customer service. However, the availablility of hourly consumption data also allows customer service at a much more personal level. Customers who query their bill are usually much more satisfied if they can view a graph or table which shows their consumption by the hour for the period in question. Higher resolution 
data, especially if it is updated live to a server, enables viewing of hourly or finer water use by customers. Such information may serve to change or reinforce water use behaviours.

\section{Acknowledgements}

The authors acknowledge the National Water Commission for providing the funding and support to make this research possible, and Wide Bay Water Corporation for providing the raw data which allowed this research to take place.

\section{References}

Athuraliya A, Gan K, Roberts P. 2008. Yarra valley water 2007 appliance stock and usage patterns survey. Yarra Valley Water, Melbourne, Australia.

Beal C, Stewart RA, Huang T. 2010. South-east Queensland residential end use study: baseline results - winter 2010. Urban Water Security Research Alliance Technical Report No. 31.

Beal, C., Stewart, R.A., Huang, T.T., Rey, E., 2011. SEQ residential end use study. Journal of the Australian Water Association 38 (1), 80-84.

Blokker E, Vreeburg J, Van Dijk J. 2010. Simulating residential water demand with a stochastic end use model. Journal of Water Resources Planning and Management 136, $19-26$.

Britton, T., Cole, G., Stewart, R., Wisker, D. 2008. Remote diagnosis of leakage in residential households. Water: Journal of the Australian Water Association, 35(6), 89-93.

Carragher, B.J., Stewart, R.A., Beal, C.D. 2012. Quantifying the influence of residential water appliance efficiency on average day diurnal demand patterns at an end use level: A precursor to optimised water service infrastructure planning. Resources, Conservation and Recycling 62, 81-90. 
Cole, G., O’Halloran, K., Stewart, R.A. 2012. Time of use tariffs: implications for water efficiency. Water Science \& Technology: Water Supply, 12(1), 90-100.

Cole, G. 2011, Time of use tariffs: reforming the economics of urban water supply, Waterlines report, National Water Commission, Canberra, pp. 40-49

Firth S, Lomas K, Wright A, Wall R. 2008. Identifying trends in the use of domestic appliances from household electricity consumption measurements. Energy and Buildings 40, 926 - 936.

Fidar A., Memon F., Butler D. 2010. Environmental implications of water efficient microcomponents in residential buildings. Science of the Total Environment, 408, 5828 5835.

Hauber-Davis, G., Idris, E. 2006. Smart Water Metering. Water: Journal of the Australian Water Association, 33(3), 56-59.

Idris, E. 2006. Smart metering: a significant component of integrated water conservation system, Proceedings of the 1st Australian Young Water Professionals Conference. International Water Association, Sydney.

Kappel, K. \& Grechenig, T. 2009, 'Show-Me: Water consumption at a glance to promote water conservation in the shower', in Proceedings of the 4th International Conference on Persuasive Technology, no. 350, pp. 1-6.

Loh, M., Coghlan, P., 2003. Domestic Water Use In Perth, Western Australia, Water Corporation, Perth, Australia. Pp. 21-31

McDonald, A.T, 2007, Chapter 2 'Water Needs: The Demand for Water’, Sustainable Water: Chemical Science Priorities, Royal Society of Chemistry Report, p.11, PDF available at http://www.rsc.org/scienceandtechnolo

gy/policy/documents/water.asp 
Makki, A.A., Stewart, R.A., Panuwatwanich, K., Beal, C., 2011. Revealing the determinants of shower water end use consumption: enabling better targeted urban water conservation strategies, Journal of Cleaner Production, in-press, doi:10.1016/j.jclepro.2011.08.007

McIntyre, T.J. 2008. Data retention in Ireland: Privacy, policy and proportionality. Computer Law \& Security Report 24(4), 326-334.

Micou, A.P., Mitchell, G., McDonald, A., 2012. Sustainable homes: a methodology for assessing influence on regional water demand, Water Science \& Technology: Water Supply, 12(2), 140-147.

NYSERDA 2003. A Primer on Smart Metering. New York State Energy Research and Development Authority. Available online at: http://sites.energetics.com/madri/toolbox/ pdfs/background/primer.pdf.

Polebitski, A.S., Palmer, R.N., 2010. Seasonal residential water demand forecasting for census tracts. Journal of Water Resources Planning and Management, 136(1), 27-37.

Queensland Department of Environment and Resource Management, 2010, Planning Guidelines for Water Supply and Sewerage, p.3

Makropoulos CK, Natsis K, Liu S, Mittas K, Butler D. 2008. Decision support for sustainable option selection in integrated urban water management. Environmental Modelling \& Software 23, 1448 - 1460.

Mayer PW, DeOreo, WB. 1998. Residential end uses of water. Aquacraft Inc. Water Engineering and Management, Boulder, USA.

Neenan, B., Hempill, R. 2008. Social benefits of smart metering investments. The Electricity Journal 21(8), 32-45.

Stewart, R. A., Willis, R., Giurco, D., Panuwatwanich, K., Capati, G., 2010. Web-based knowledge management system: linking smart metering to the future of urban water planning. Australian Planner, 47, 66 - 74. 
Taylor, B.A., 2012. Predicting normalised monthly patterns of domestic external water demand using rainfall and temperature data. Water Science \& Technology: Water Supply, 12(2), 168-178.

The National Water Commission, 2010, The National Performance Report 2009-10 Urban Water Utilities pp. 127-128, 167-168 and 315-316, available at http://www.nwc.gov.au/www/html/3031-npr-urban-2009-10.asp?intSiteID=1

Wilby, R. and Miller. K; 2009 Technical Briefing Paper 8: Water Demand Impacts and Utility Responses, Water Research Foundation. Synopsis available at $<$ http://www.theclimatechangeclearinghouse.org/Resources/TechBrief/Technical\%20Bri efings\%20Document\%20Library/(8)\%20Water\%20Demand\%20Impacts\%20and\%20Uti lity\%20Responses.pdf>

Willis, R. M. D., Stewart, R., Panuwatwanich, K., Capati, B., Giurco, D., 2009. Gold Coast domestic water end use study. Journal of Australian Water Association. 36 (6), 79-85.

Willis, R.M., Stewart, R.A., Panuwatwanich, K., Jones, S., Kyriakides A., 2010. Alarming visual display monitors affecting shower end use water and energy conservation in Australian residential households. Resources, Conservation and Recycling 54(12), 11171127.

Willis, R.M., Stewart, R.A., Giurco, D.P., Talebpour, M.R., 2011a. End use water consumption in households: impact of socio-demographic factors and efficient devices, Journal of Cleaner Production, in-press, doi:10.1016/j.jclepro.2011.08.006

Willis, R.M., Stewart, R.A., Williams, P., Hacker, C., Emmonds, S., Capati, G., 2011b. Residential potable and recycled water end uses in a dual reticulated supply system. Desalination 272 (1-3), 201-211. 
Table 1. Indoor residential indoor water end usage in Perth from 1998 to 2000 (adapted from Loh and Coghlan, 2001)

\begin{tabular}{|c|c|c|c|c|}
\hline \multirow[b]{3}{*}{ Appliance category } & \multicolumn{4}{|c|}{ Dwelling type } \\
\hline & \multicolumn{2}{|c|}{ Single residential } & \multicolumn{2}{|c|}{ Multi-residential } \\
\hline & $\begin{array}{r}\text { Consumption } \\
(\mathrm{L} / \mathrm{hh} / \mathrm{d})\end{array}$ & $\begin{array}{r}\text { Proportion of } \\
\text { indoor usage (\%) }\end{array}$ & $\begin{array}{r}\text { Consumption } \\
(\mathrm{L} / \mathrm{hh} / \mathrm{d})\end{array}$ & $\begin{array}{r}\text { Proportion of } \\
\text { indoor usage }(\%)\end{array}$ \\
\hline Bath or shower & 171 & 33 & 121 & 33 \\
\hline Washing machine & 139 & 27 & 94 & 26 \\
\hline Toilet & 112 & 21 & 62 & 17 \\
\hline Tap & 83 & 16 & 77 & 21 \\
\hline Other $^{\#}$ & 18 & 3 & 11 & 3 \\
\hline Total & 523 & 100 & 365 & 100 \\
\hline
\end{tabular}

\#includes dish washers, spas and evaporative air conditioners

Table 2. Total connections in each DMA and average residential property size

\begin{tabular}{lrrrr}
\hline Dwelling type/DMA \# & DMA 4 & DMA 10 & DMA 21 & DMA 36 \\
\hline Single residential & 1,177 & 437 & 685 & 195 \\
Multiple residential & 235 & 3 & 10 & 142 \\
Average single residential property size $\left(\mathrm{m}^{2}\right)$ & 832 & 3,155 & 1,392 & 521 \\
\hline
\end{tabular}

Table 3. Comparing 5 years of rainfall and temperature parameters for the month in which maximum day consumption occurred

\begin{tabular}{llrrr}
\hline Year & Month & $\begin{array}{r}\text { Max day } \\
\text { consumption (ML) }\end{array}$ & $\begin{array}{r}\text { Total monthly } \\
\text { rainfall (mm) }\end{array}$ & $\begin{array}{r}\text { Average max } \\
\text { daily temperature }\end{array}$ \\
\hline $2004 / 2005$ & January & 27.58 & 147.4 & 29.7 \\
$2005 / 2006$ & January & 24.18 & 188.2 & 31.1 \\
$2006 / 2007$ & March & 30.43 & 50.2 & 30.9 \\
$2007 / 2008$ & December & 28.29 & 94.8 & 28.9 \\
$2008 / 2009$ & December & 26.14 & 37.8 & 30.8 \\
\hline
\end{tabular}

Source: http://www.weatherzone.com.au 
Table 4. Comparing rainfall, temperature and average maximum monthly consumption during the 5 hottest months over 5 years

\begin{tabular}{lrrr}
\hline Months/Year & $\begin{array}{r}\text { Average daily } \\
\text { max temp }\left({ }^{\circ} \mathrm{C}\right)\end{array}$ & $\begin{array}{r}\text { Average summer } \\
\text { monthly max day }\end{array}$ \\
\hline Nov/Mar 2007/08 & 28.8 & 133.7 & 20.3 \\
Nov/Mar 2005/06 & 30.1 & 119.2 & 21.4 \\
Nov/Mar 2008/09 & 29.5 & 115.9 & 23.2 \\
Nov/Mar 2004/05 & 28.7 & 111.6 & 24.2 \\
Nov/Mar 2006/07 & 29.7 & 64.7 & 25.5 \\
\hline
\end{tabular}

Source: http://www.weatherzone.com.au

Table 5. Understanding likely water usage profiles for hourly time intervals

\begin{tabular}{|c|c|c|c|c|}
\hline Time & 1st $\dagger$ & 2nd & 3rd & Purpose \\
\hline 12am-1am & 10 & 20 & 30 & Toilet, hygiene \\
\hline $1 \mathrm{am}-2 \mathrm{am}$ & 10 & 20 & $>1200$ & Toilet, hygiene, irrigation \\
\hline 2am-3am & 10 & $>1200$ & 20 & Toilet, hygiene, irrigation \\
\hline 3am-4am & 10 & 20 & $>1200$ & Toilet, hygiene, irrigation \\
\hline 4am-5am & 10 & 20 & $>1200$ & Toilet, hygiene, irrigation \\
\hline 5am-6am & 10 & 20 & $>1200$ & Toilet, hygiene, irrigation \\
\hline 6am-7am & 10 & 20 & 30 & Toilet, hygiene \\
\hline 7am-8am & $>100<=120$ & $>200<=250$ & $>120<=140$ & Toilet, hygiene, shower, breakfast, dishwasher \\
\hline 8am-9am & $>200<=250$ & $>100<=120$ & $>120<=140$ & Toilet, hygiene, shower, breakfast, dishwasher \\
\hline 9am-10am & $>200<=250$ & $>100<=120$ & $>120<=140$ & Washing, toilet, hygiene, shower, dishwasher \\
\hline 10am-11am & $>200<=250$ & $>100<=120$ & $>120<=140$ & Washing, toilet, hygiene, shower, dishwasher \\
\hline 11am-12pm & $>200<=250$ & $>100<=120$ & $>120<=140$ & Washing, toilet, hygiene, shower, dishwasher \\
\hline 12pm-1pm & 10 & $>200<=250$ & 20 & Toilet, hygiene, lunch, dishwasher \\
\hline 1pm-2pm & 10 & 20 & $>100<=120$ & Toilet, hygiene, lunch, dishwasher \\
\hline 2pm-3pm & 10 & 20 & 30 & Toilet, hygiene \\
\hline $3 p m-4 p m$ & 10 & 20 & 30 & Toilet, hygiene \\
\hline $4 \mathrm{pm}-5 \mathrm{pm}$ & 10 & 20 & $>200<=250$ & Toilet, hygiene, dishwasher, clothes washer \\
\hline $5 \mathrm{pm}-6 \mathrm{pm}$ & 10 & $>200<=250$ & 20 & Toilet, hygiene, shower, dishwasher, clothes washer \\
\hline $6 \mathrm{pm}-7 \mathrm{pm}$ & $>200<=250$ & $>100<=120$ & 10 & Toilet, hygiene, dinner, shower, dishwashing \\
\hline 7pm-8pm & 20 & 10 & $>100<=120$ & Toilet, hygiene, dinner, shower, dishwashing \\
\hline 8pm-9pm & 10 & 20 & $>100<=120$ & Toilet, hygiene, dinner, shower, dishwashing \\
\hline 9pm-10pm & 10 & 20 & 30 & Toilet, hygiene \\
\hline 10pm-11pm & 10 & 20 & 30 & Toilet, hygiene \\
\hline 11pm-12am & 10 & 20 & 30 & Toilet, hygiene \\
\hline
\end{tabular}

${ }^{\dagger}$ Volume ranges ranked by highest volume of use by the hour (in L) 
Table 36. Typical water use types for various volume ranges

Typical uses for water at various volumes per hour

\begin{tabular}{|c|c|c|c|}
\hline $10^{\dagger}-100 \mathrm{~L}$ & $>100<=300 \mathrm{~L}$ & $>300<=600 \mathrm{~L}$ & $>600 \mathrm{~L}$ \\
\hline Toilet flush $^{\ddagger}$ & $\begin{array}{l}\text { Multiple use and/or } \\
\text { combinations of types }\end{array}$ & Outdoor use & Outdoor use \\
\hline $\begin{array}{l}\text { Personal hygiene } \\
\text { (washing hands etc) }\end{array}$ & Toilet flush & $\begin{array}{l}\text { Multiple use and/or } \\
\text { combinations of types }\end{array}$ & $\begin{array}{l}\text { Multiple use and/or } \\
\text { combinations of types }\end{array}$ \\
\hline Cooking/drinking & $\begin{array}{l}\text { Personal hygiene } \\
\text { (washing hands etc) }\end{array}$ & Washing machine & Washing machine \\
\hline Shower/bath & Cooking/drinking & Dishwashing & Dishwashing \\
\hline Dishwashing & Shower/bath & Shower/bath & Shower/bath \\
\hline $\begin{array}{l}\text { Multiple use and/or } \\
\text { combinations of types }\end{array}$ & Dishwashing & Cooking/drinking & Cooking/drinking \\
\hline Washing machine & Washing machine & Toilet flush & Toilet flush \\
\hline Outdoor use & Outdoor use & $\begin{array}{l}\text { Personal hygiene } \\
\text { (washing hands etc) }\end{array}$ & $\begin{array}{l}\text { Personal hygiene } \\
\text { (washing hands etc) }\end{array}$ \\
\hline All the above & All the above & All the above & All the above \\
\hline
\end{tabular}

$\dagger 10 \mathrm{~L}$ per hour minimum resolution of meter; ${ }^{\ddagger}$ ranked in order of likelihood in water use range.

Table 7. Single residential and multi residential consumption comparison by DMA and property size

\begin{tabular}{lrrrrrrrrrrr}
\hline \multirow{3}{*}{ Volume range (L/hr) } & \multicolumn{2}{c}{$\begin{array}{l}\text { DMA 4 } \\
\left(832 \mathrm{~m}^{2}\right)\end{array}$} & \multicolumn{2}{c}{$\begin{array}{c}\text { DMA 10 } \\
\left(3155 \mathrm{~m}^{2}\right)\end{array}$} & \multicolumn{2}{c}{$\begin{array}{c}\text { DMA 21 } \\
\left(1392 \mathrm{~m}^{2}\right)\end{array}$} & \multicolumn{2}{c}{$\begin{array}{c}\text { DMA 36 } \\
\left(521 \mathrm{~m}^{2}\right)\end{array}$} & $\begin{array}{c}\text { Multi-residential } \\
\left(<300 \mathrm{~m}^{2}\right)\end{array}$ \\
\cline { 2 - 13 } & L/Conn & $(\%)$ & L/Conn & $(\%)$ & L/Conn & $(\%)$ & L/Conn & $(\%)$ & L/Conn & $(\%)$ \\
\hline 10 to 100 & 237.3 & 48.1 & 231.9 & 39.1 & 219.0 & 40.2 & 201.6 & 54.2 & 182.3 & 56.2 \\
$>100<=300$ & 172.3 & 34.9 & 167.1 & 28.2 & 180.0 & 33.2 & 124.5 & 33.4 & 115.1 & 35.5 \\
$>300<=600$ & 42.3 & 8.6 & 68.1 & 11.4 & 58.4 & 10.8 & 25.6 & 6.9 & 17.7 & 5.4 \\
$>600$ & 41.3 & 8.4 & 126.1 & 21.3 & 85.3 & 15.7 & 20.3 & 5.5 & 9.2 & 2.9 \\
\hline Total & 493.2 & 100 & 593.2 & 100 & 542.7 & 100 & 372.0 & 100 & 324.3 & 100 \\
\hline
\end{tabular}


Table 8. Monthly peak consumption figures for all property types from 1 July 2008 to 30 June 2009

\begin{tabular}{llll}
\hline Month & $\begin{array}{l}\text { Single residential } \\
(\mathrm{L})\end{array}$ & $\begin{array}{l}\text { Multi- residential } \\
(\mathrm{L})\end{array}$ & $\begin{array}{l}\text { All residential } \\
(\mathrm{L})\end{array}$ \\
\hline July & 125,610 & 15,660 & 141,030 \\
August & 135,070 & 15,440 & 146,700 \\
September & 164,030 & 14,460 & 172,840 \\
October & 190,940 & 15,610 & 200,990 \\
November & 204,240 & 14,750 & 212,730 \\
December & 226,550 & 13,270 & 238,340 \\
January & 215,300 & 12,970 & 224,150 \\
February & 176,610 & 13,430 & 185,150 \\
March & 154,030 & 14,310 & 163,440 \\
April & 127,650 & 12,940 & 137,550 \\
May & 123,920 & 12,800 & 136,720 \\
June & 110,780 & 14,390 & 122,920 \\
\hline
\end{tabular}

Table 9. Comparison of monthly peak hour demand as a percentage of the annual peak hour (all connections)

\begin{tabular}{lll}
\hline Month & $\begin{array}{l}\text { Peak hour } \\
\text { demand (L) }\end{array}$ & $\begin{array}{l}\text { Proportion of annual } \\
\text { peak hour demand (\%) }\end{array}$ \\
\hline July & 150,420 & 56.16 \\
August & 160,040 & 59.75 \\
September & 187,060 & 69.84 \\
October & 222,990 & 83.25 \\
November & 229,950 & 85.85 \\
December & 267,840 & 100.00 \\
January & 257,440 & 96.12 \\
February & 205,550 & 76.74 \\
March & 185,310 & 69.19 \\
April & 157,540 & 58.82 \\
May & 158,530 & 59.19 \\
June & 149,090 & 55.66 \\
\hline
\end{tabular}


Table 10. Annual peak hour consumption by property type compared to average morning and evening peak hour consumption

\begin{tabular}{lll}
\hline Property type & Single residential (L) & Multi-residential (L) \\
\hline Annual peak hour consumption & $226,550(100.00 \%)^{\dagger}$ & $11,790(100.00 \%)^{\dagger}$ \\
Average morning peak hour consumption & $108,113(47.72 \%)^{\dagger}$ & $11,063(93.83 \%)^{\dagger}$ \\
Average evening peak hour consumption & $101,100(44.62 \%)^{\dagger}$ & $7,761(65.82 \%)^{\dagger}$ \\
\hline
\end{tabular}

${ }^{\dagger}$ value in parenthesis denotes the percent of peak hour consumption

Table 11. Annual maximum peak hour consumption by property type and volume range

\begin{tabular}{lllll}
\hline L/hr range & $\begin{array}{l}\text { Single residential } \\
\text { peak hour (L) }\end{array}$ & $\begin{array}{l}\text { Single residential } \\
\text { average evening peak } \\
\text { hour (L) }\end{array}$ & $\begin{array}{l}\text { Multi- } \\
\text { residential } \\
\text { peak hour (L) }\end{array}$ & $\begin{array}{l}\text { Multi-residential } \\
\text { average evening } \\
\text { peak hour (L) }\end{array}$ \\
\hline$<=100$ & 35,540 & $36,090(101.54 \%)^{\dagger}$ & 4,300 & $4,209(97.88 \%)^{\dagger}$ \\
$>100<=300$ & 40,680 & $31,401(77.19 \%)^{\dagger}$ & 3,890 & $2,840(73.01 \%)^{\dagger}$ \\
$>300<=600$ & 49,940 & $14,422(28.87 \%)^{\dagger}$ & 290 & $564(194.48 \%)^{\dagger}$ \\
$>600$ & 100,390 & $19,186(19.11 \%)^{\dagger}$ & 810 & $149(18.40 \%)^{\dagger}$ \\
\hline Total consumption & 226,550 & $101,100(44.62 \%)^{\dagger}$ & 11,790 & $7762(65.00 \%)^{\dagger}$ \\
\hline
\end{tabular}

${ }^{\dagger}$ value in parenthesis denotes the percent of peak hour consumption

Table 12. Breakdown of connections using water in different volumes during peak hour

\begin{tabular}{lllll}
\hline L/hr range & $\begin{array}{l}\text { Single residential } \\
\text { connections }\end{array}$ & Percent (\%) & $\begin{array}{l}\text { Multi-residential } \\
\text { Connections }\end{array}$ & Percent (\%) \\
\hline$<=100$ & 1,147 & 45.99 & 149 & 38.20 \\
$>100<=300$ & 227 & 9.10 & 24 & 6.15 \\
$>300<=600$ & 112 & 4.49 & 7 & 1.79 \\
$>600$ & 105 & 4.21 & 1 & 0.25 \\
\hline Total connections & & & & 46.41 \\
recording consumption & 1,591 & 63.79 & 181 & 4 \\
\hline
\end{tabular}


Table 13. Comparison of per/connection annual peak hour consumption for single and multiresidential connections with consumption recorded during the annual peak hour

\begin{tabular}{llllll}
\hline \multirow{2}{*}{$\begin{array}{l}\text { Volume of } \\
\text { consumption } \\
\text { range (L/hr) }\end{array}$} & \multicolumn{5}{c}{ Average consumption per connection in each DMA (L) } \\
\cline { 2 - 6 } & $\begin{array}{l}\text { DMA 4 single } \\
\text { residential } \\
\left(832 \mathrm{~m}^{2}\right)\end{array}$ & $\begin{array}{l}\text { DMA 10 single } \\
\text { residential }\end{array}$ & $\begin{array}{l}\text { DMA 21 single } \\
\text { residential } \\
\left(3155 \mathrm{~m}^{2}\right)\end{array}$ & $\begin{array}{l}\text { DMA 36 single } \\
\text { residential } \\
\left(521 \mathrm{~m}^{2}\right)\end{array}$ & $\begin{array}{l}\text { Multi- } \\
\text { residential } \\
\left(<300 \mathrm{~m}^{2}\right)\end{array}$ \\
\hline$<=100$ & 29.96 & 32.17 & 31.7 & 32.5 & 28.86 \\
$>100<=300$ & 180.83 & 172.86 & 183.17 & 151.25 & 162.08 \\
$>300<=600$ & 439.47 & 444.67 & 472.17 & 345.00 & 398.57 \\
$>600$ & 931.94 & 947.92 & 987.44 & 815.00 & 810.00 \\
\hline
\end{tabular}

Table 14. Comparing peak day with minimum day consumption by L/connection

\begin{tabular}{lllll} 
& \multicolumn{2}{c}{$\begin{array}{c}\text { Connections with } \\
\text { recorded consumption }\end{array}$} & \multicolumn{2}{c}{$\begin{array}{c}\text { Consumption } \\
\text { per connection (L/conn.) }\end{array}$} \\
\cline { 2 - 5 } Consumption range $(\mathrm{L} / \mathrm{hr})$ & Min Day & Peak Day & Min Day & Peak Day \\
\hline$<=100$ & 2,326 & 2,419 & 254.6 & 281.3 \\
$>100<=300$ & 1,020 & 1,632 & 296.6 & 379.2 \\
$>300<=600$ & 68 & 539 & 563.2 & 683.1 \\
$>600$ & 17 & 328 & 1492.4 & 2186.8 \\
\hline Total & 2,334 & 2,457 & 410.6 & 970.6 \\
\hline
\end{tabular}

Table 15. Comparing peak day with minimum day by consumption volume

\begin{tabular}{llllll}
\hline \multirow{2}{*}{$\begin{array}{l}\text { Consumption range } \\
(\mathrm{L} / \mathrm{hr})\end{array}$} & \multicolumn{2}{c}{ Consumption (L) } & \multicolumn{2}{c}{ \% of total consumption } & \% Increase in volume \\
& Min Day & Peak Day & Min Day & Peak Day & Peak Day to Min Day \\
\hline$<=100$ & 592,200 & 680,400 & 61.8 & 28.5 & 14.90 \\
$>100<=300$ & 302,490 & 618,930 & 31.6 & 26.0 & 104.60 \\
$>300<=600$ & 38,300 & 368,190 & 4.0 & 15.4 & 861.30 \\
$>600$ & 25,370 & 717,280 & 2.6 & 30.1 & 2727.30 \\
\hline Total & 958,360 & $2,384,800$ & 100 & 100 & 248.84 \\
\hline
\end{tabular}

Table 2: Comparison of peak month consumption with minimum month consumption

\begin{tabular}{lllll}
\hline & \multicolumn{2}{c}{ Connections with recorded consumption } & \multicolumn{2}{c}{ Consumption per connection ( L) } \\
(L/hr range) & Min Month & Max Month & Min Month & Max Month \\
\hline$<=100$ & 2,533 & 2,747 & 7,221 & 7,220 \\
$>100<=300$ & 2,398 & 2,639 & 5,249 & 5,919 \\
$>300<=600$ & 1,119 & 1,997 & 1,658 & 3,858 \\
$>600$ & 320 & 1,374 & 4,820 & 9,906 \\
\hline Total & 2,535 & 2,748 & 13,521 & 20,658 \\
\hline
\end{tabular}




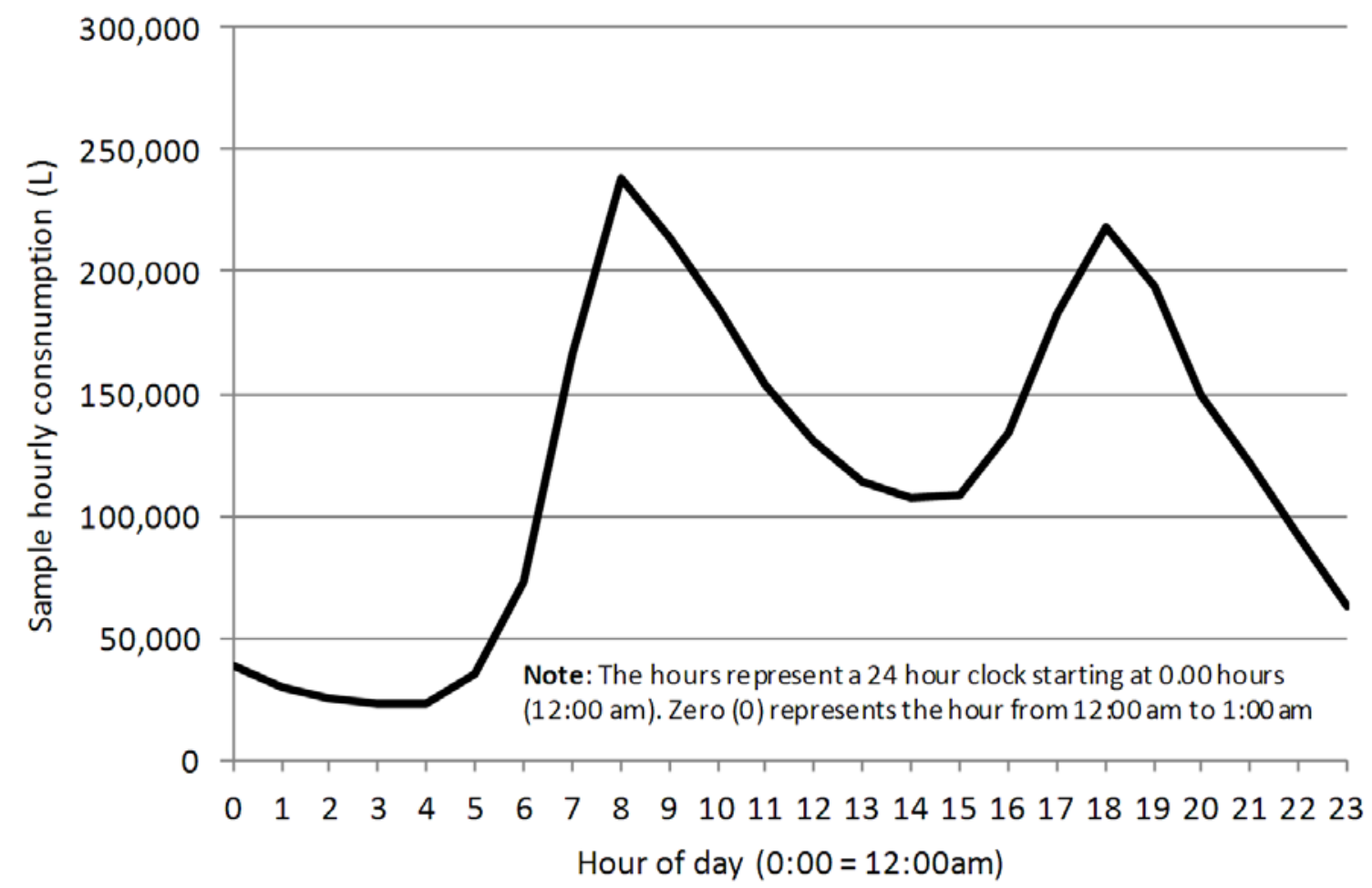

Figure 1. Diurnal pattern of average hourly consumption for 2,884 sampled connections 


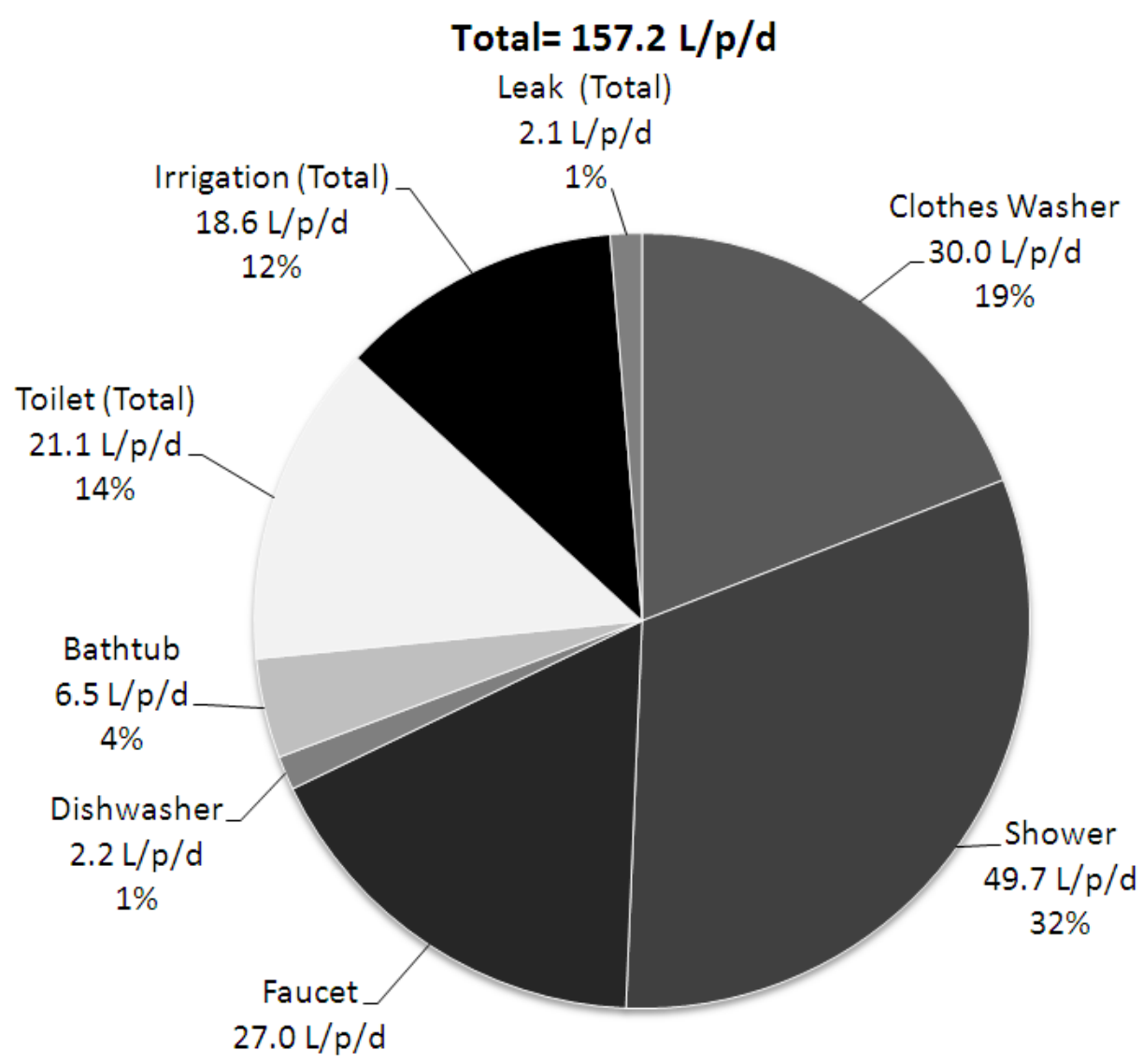

Figure 2. Gold Coast City water end use study breakdown (Willis et al. 2009) 


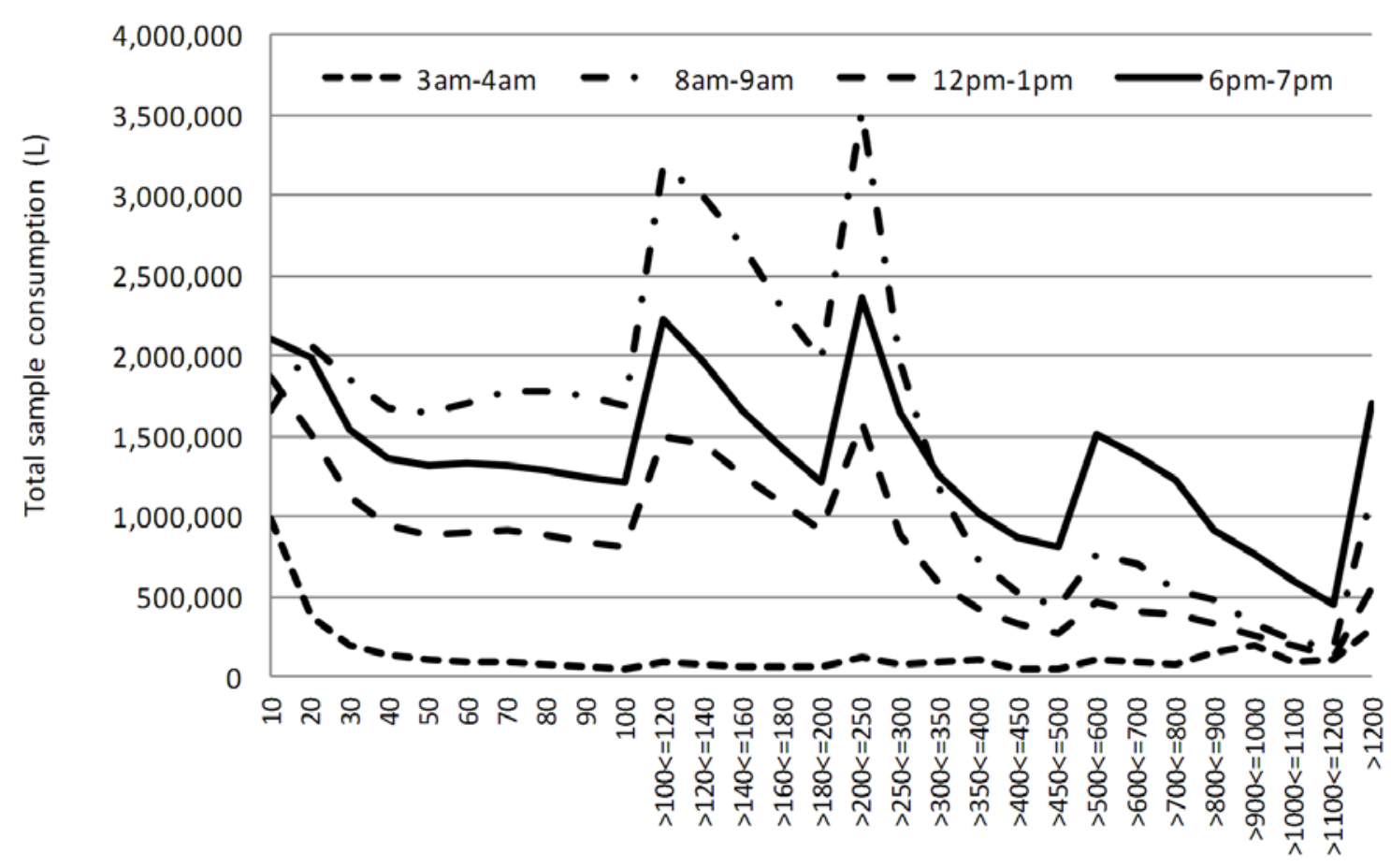

Consumption volume interval categories $(\mathrm{L} / \mathrm{hr})$

Figure 3. The breakdown by volume range of average hourly consumption in four selected hour periods for the 2,884 residential connections

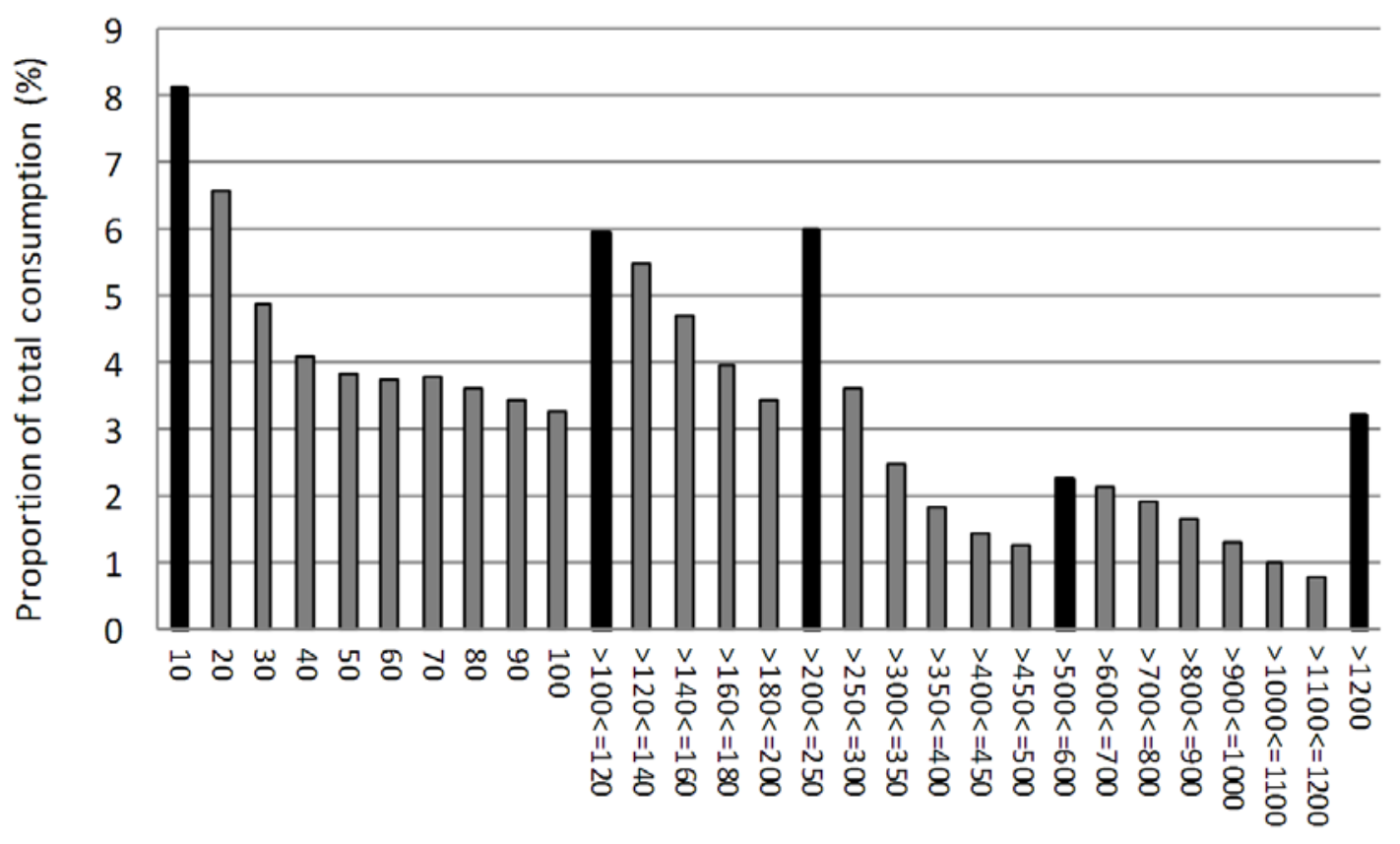

Consumption volume ranges $(\mathrm{L})$

Figure 4. Proportion of total consumption in each volume range 


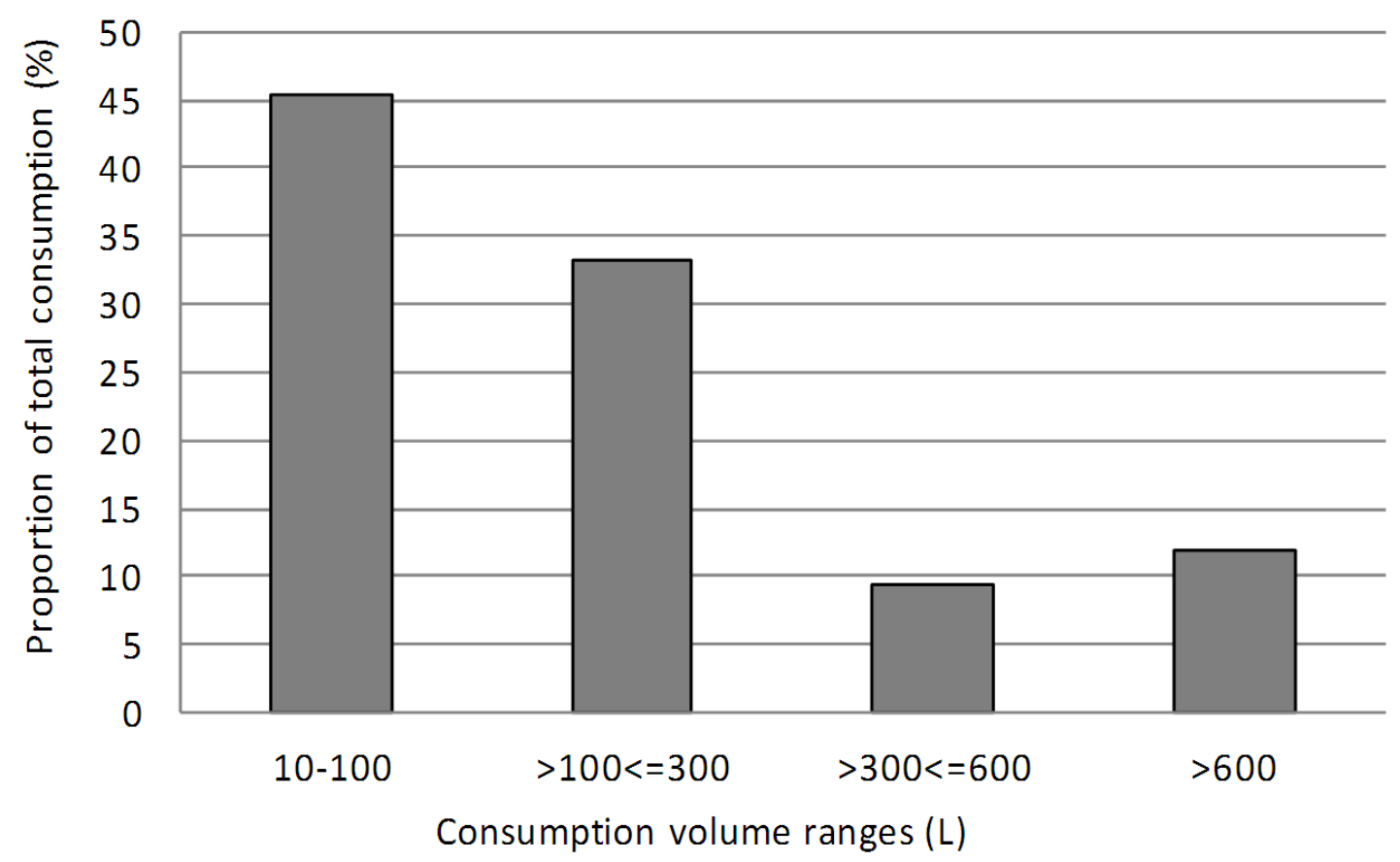

Figure 5. Proportion of consumption in four volume ranges as \% of total consumption

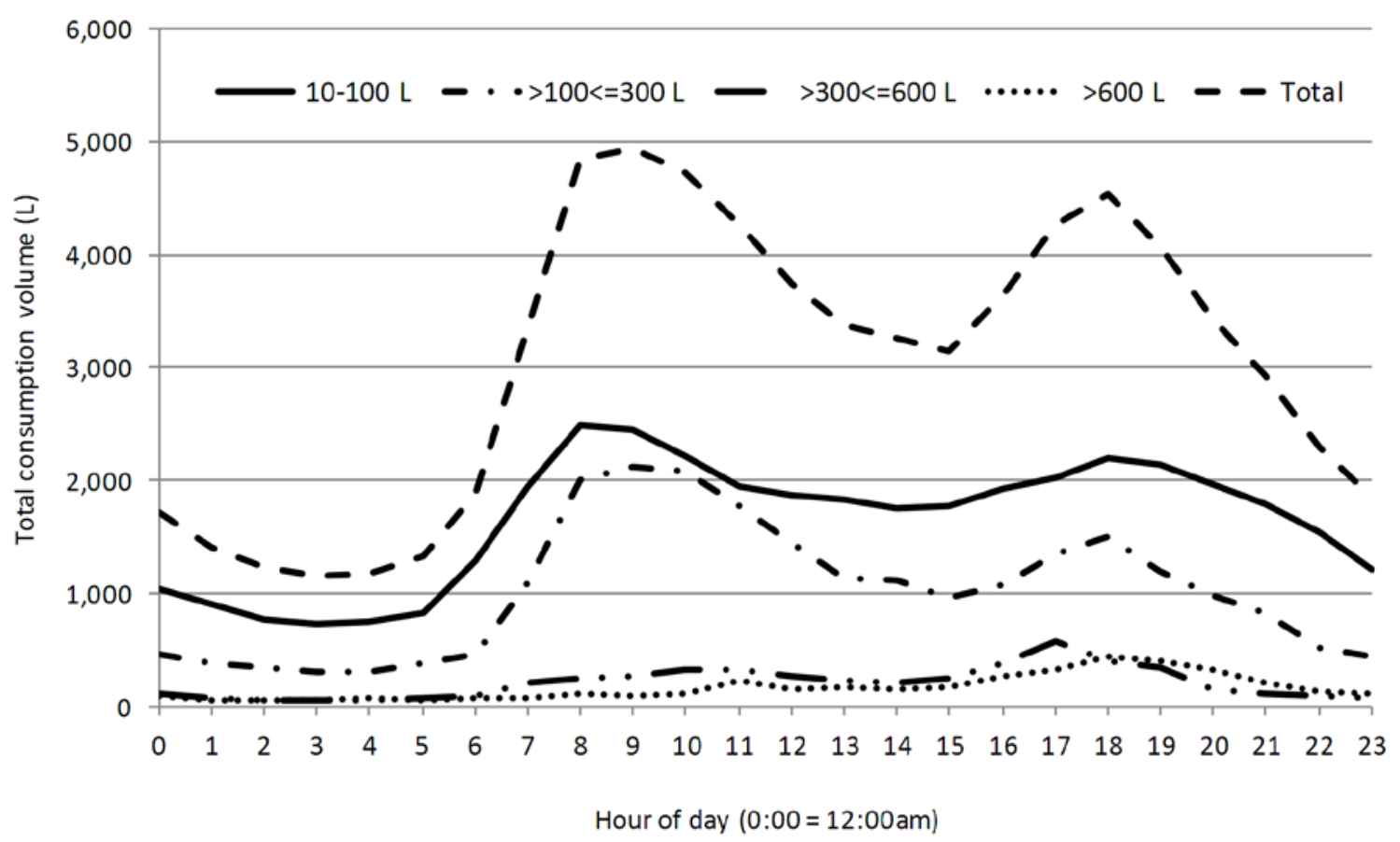

Figure 6. DMA 36 average hourly consumption for four volume ranges over the period 1 July 2008 to 30 June 2009 


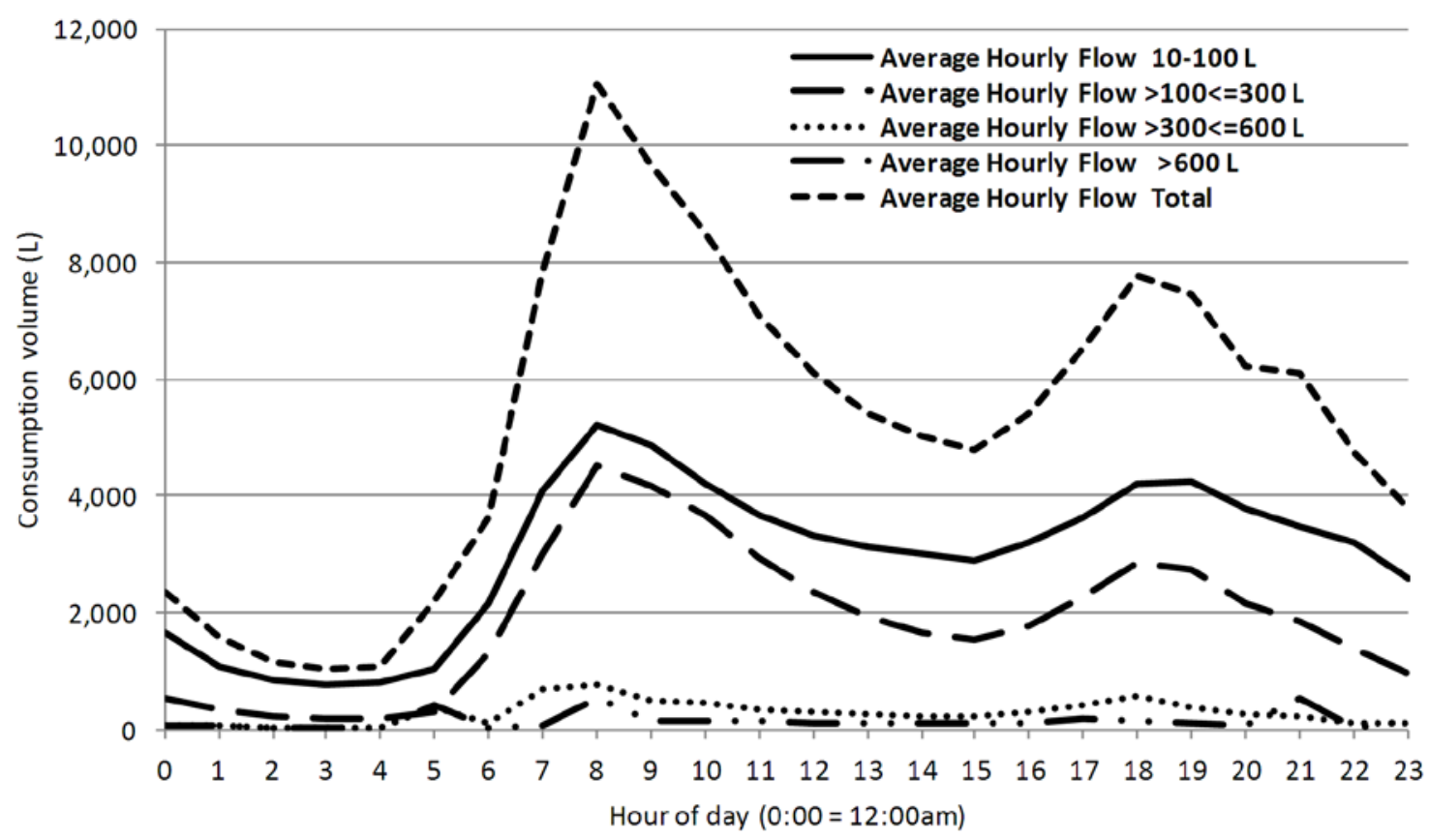

Figure 7. Multi-residential average hourly consumption $(n=390)$ for four volume ranges over the period 1 July 2008 to 30 June 2009

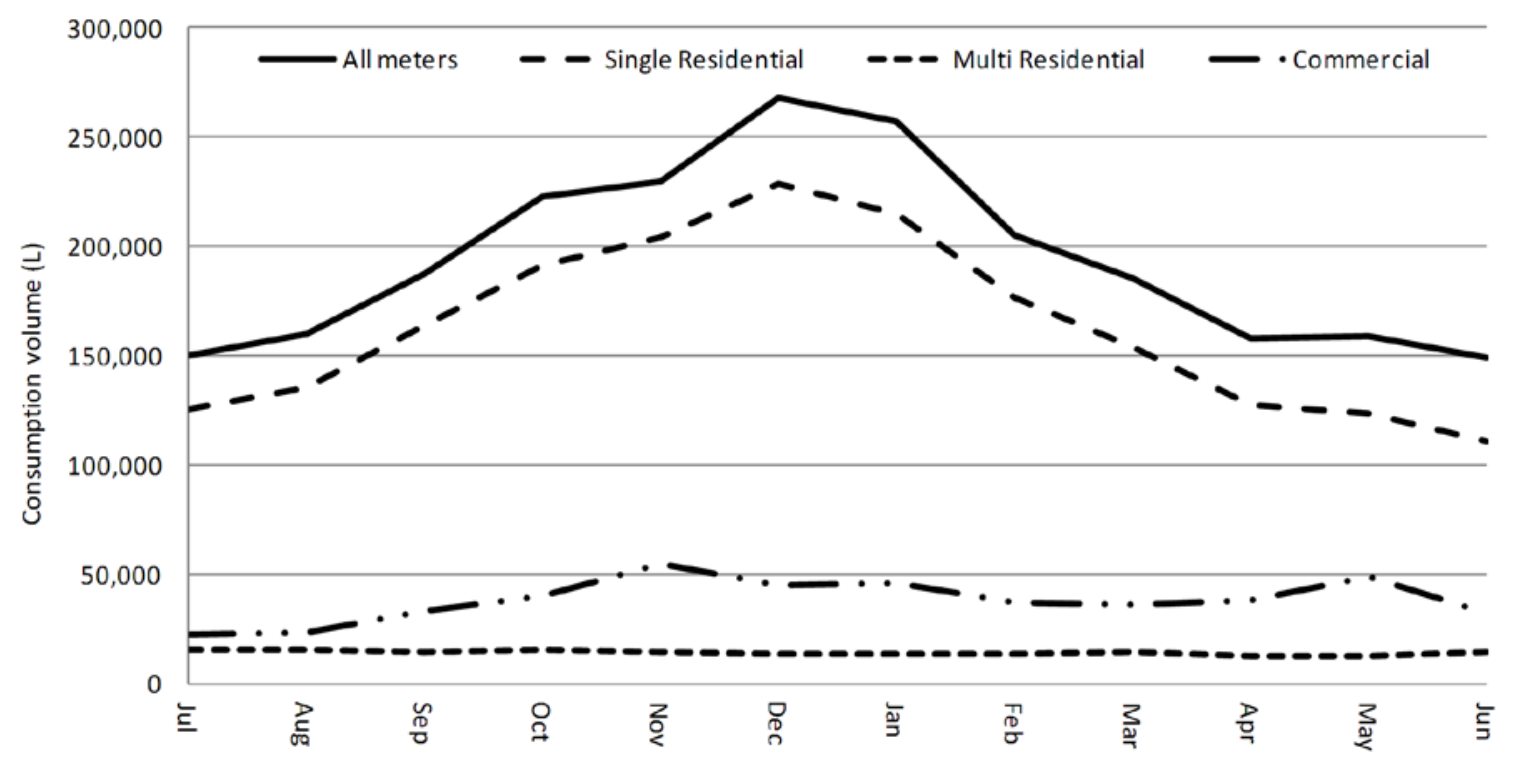

Figure 8. Monthly peak hour demand for all property types from 1 July 2008 to 30 June 2009 


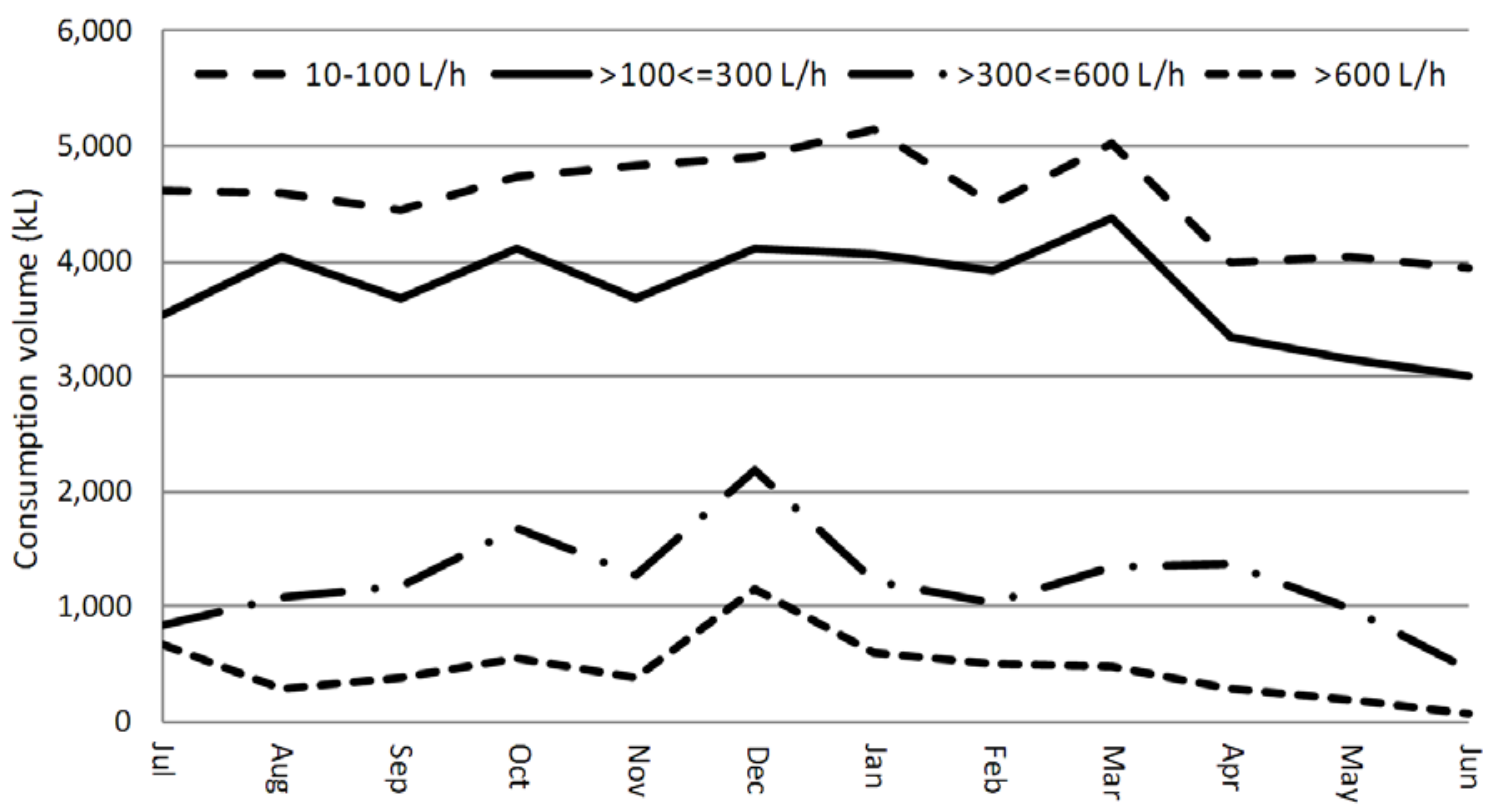

Figure 9. Monthly consumption in four volume ranges in DMA $21(n=695)$ for the duration 1 July 2008 to 30 June 2009

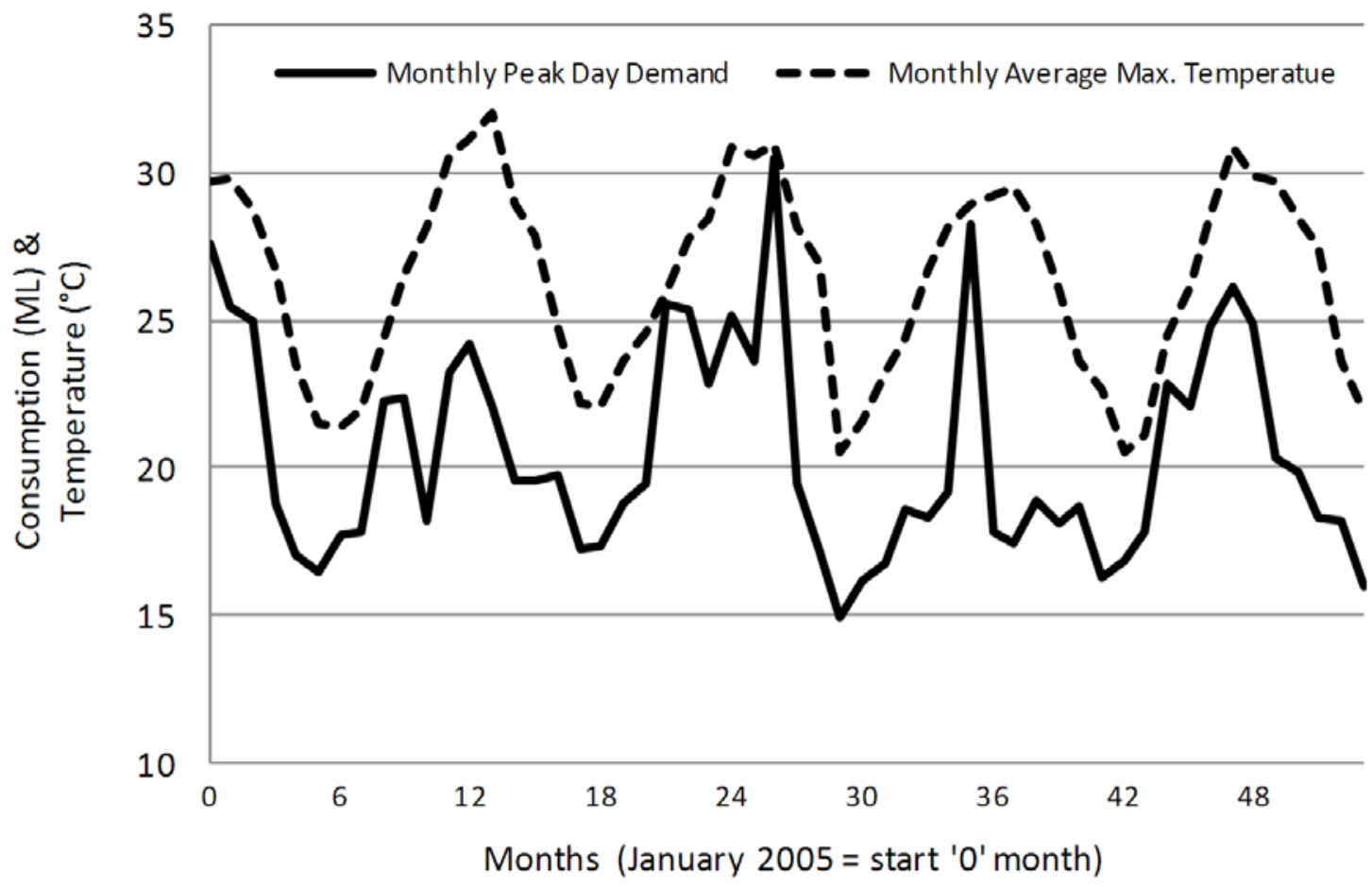

Figure 10. Hervey Bay monthly peak water demand and monthly average max temperature for period January 2005 to June 2009 (Month 0 to 54) 


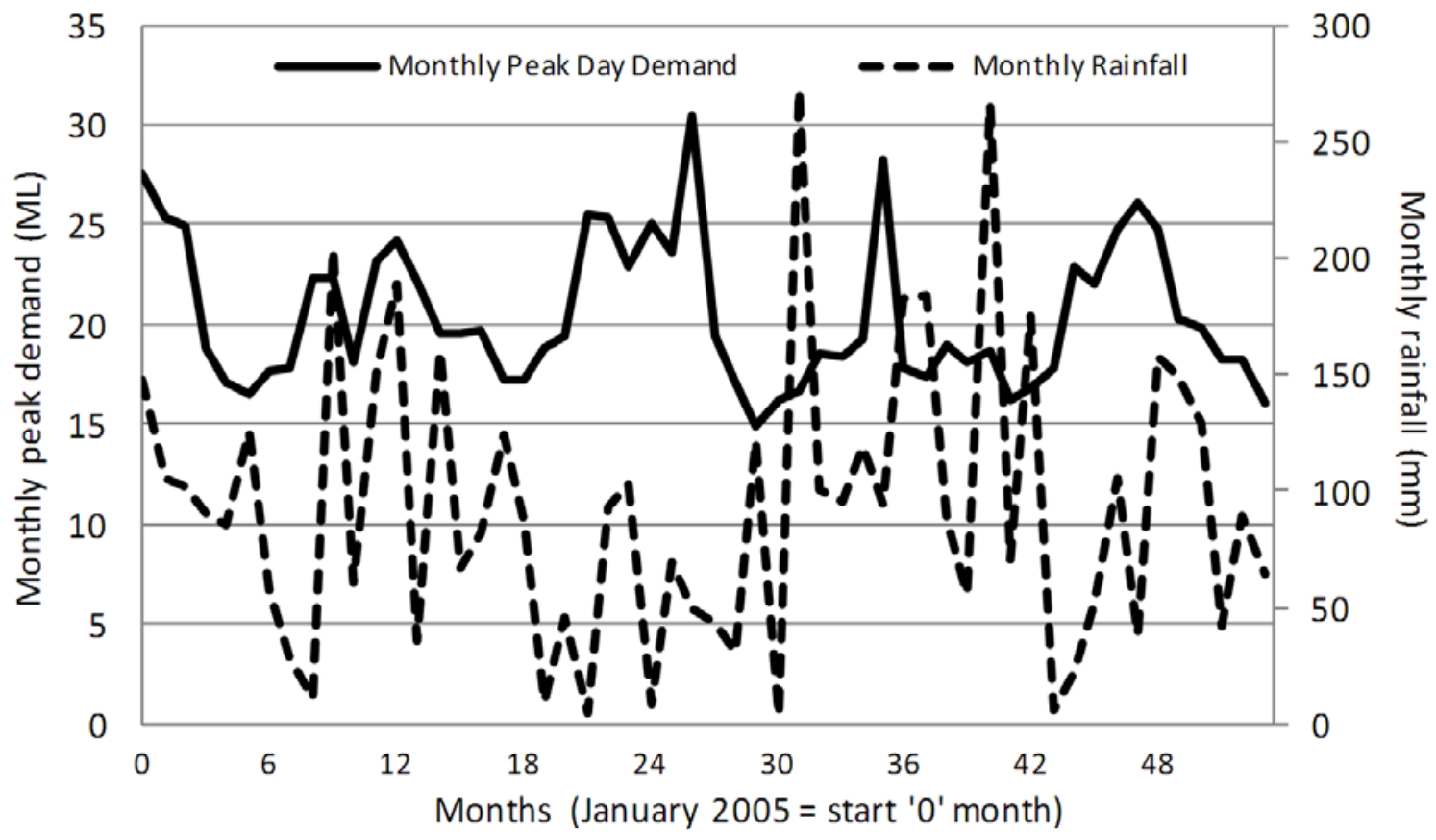

Figure 11. Hervey Bay monthly peak demand and monthly average monthly rainfall for period January 2005 to June 2009 (Month 0 to 54)

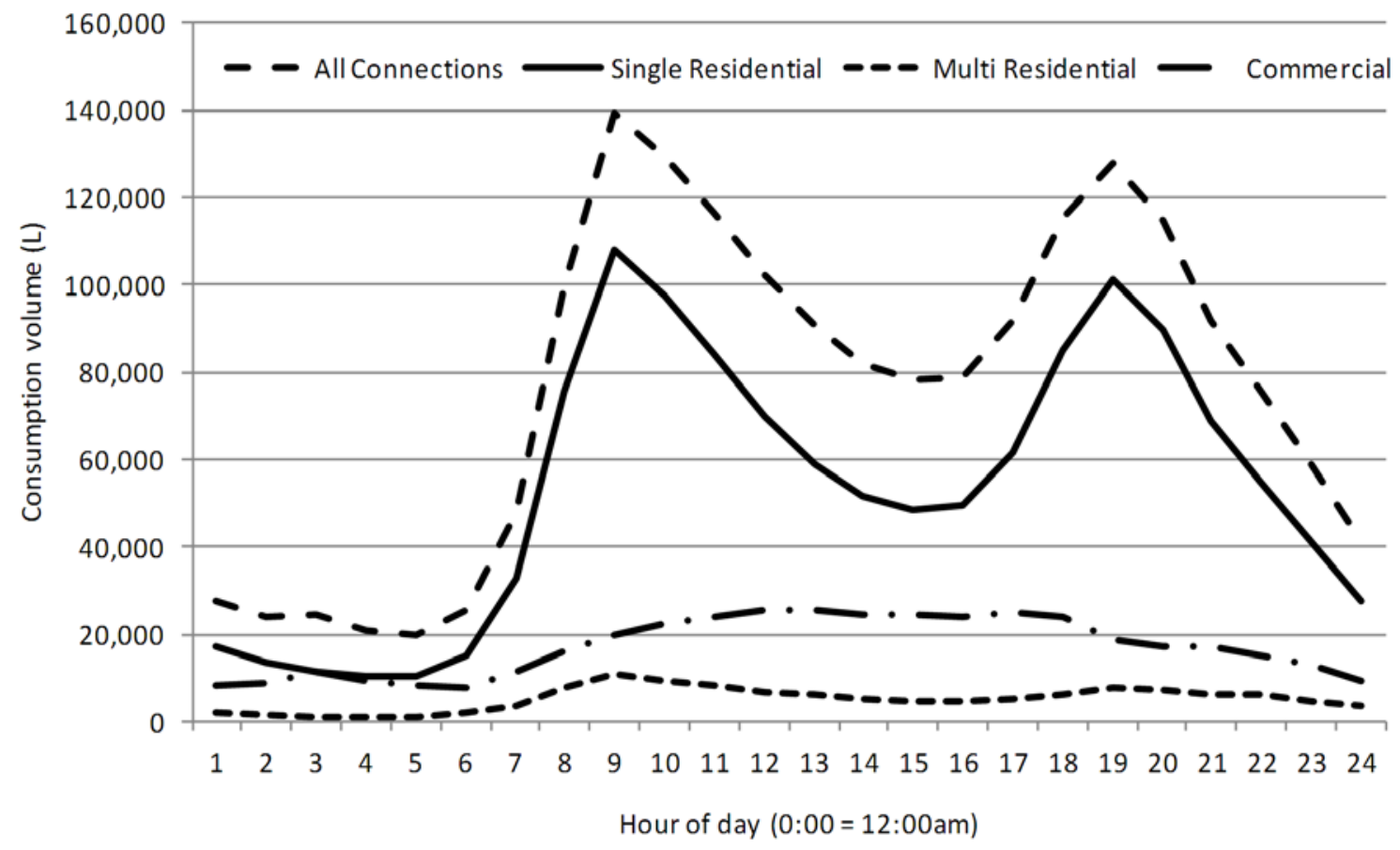

Figure 12. Comparison of diurnal pattern by property type 